\title{
Effects of a capital gains tax on asset pricing
}

\author{
Marko Volker Krause ${ }^{1}$
}

Received: 21 April 2016/Accepted: 23 November 2017/Published online: 4 December 2017

(C) The Author(s) 2017. This article is an open access publication

\begin{abstract}
I extend and generalize the work of Kruschwitz and Löffler (BuRBusiness Research 2(2):171-178, 2009). I find that, with a zero risk-free rate, the implicit price of capital gains tax payments is zero. I provide conditions in stochastic discount factor language when a capital gains tax has no effect on asset prices for the case of a zero risk-free rate. A sufficient condition for price equality with a zero risk-fee rate is that agents consume the same in any state with and without taxes. Equilibria exist that guarantee equal consumptions, and they imply the same portfolio rules that Kruschwitz and Löffler (BuR-Business Research 2(2):171-178, 2009) find for the CAPM. Furthermore, for an exogenous non-zero risk-free rate, I show that exponential utility with multivariate normal payoffs, as well as linear marginal utility leave prices unchanged. Equilibrium prices are independent of capital gains taxes in those cases. However, total wealth of agents is different between the tax and the no-tax economy.
\end{abstract}

Keywords Capital gains tax $\cdot$ Stochastic discount factor $\cdot$ Portfolio theory $\cdot$ Constant absolute risk aversion $\cdot$ Linear marginal utility

JEL Classification G11 - G12

Marko Volker Krause

marko.krause@capco.com

1 Capco-The Capital Markets Company GmbH, Opernplatz 14, 60313 Frankfurt am Main, Germany 


\section{Introduction}

I build on the work of Kruschwitz and Löffler (2009) who assumed a single-period mean-variance capital asset pricing model (CAPM) with a flat tax on capital gains and tax transfers back to investors. They find that prices in a world with taxes on returns are the same as prices in a world without taxes if the risk-free rate is zero or investors have constant absolute risk aversion mean-variance utility. Instead of regarding a mean-variance CAPM as in Kruschwitz and Löffler (2009), I construct a model with agents that value expected utility over consumption, i.e., a consumption CAPM with heterogeneous agents. The fundamental results from Kruschwitz and Löffler (2009) also hold for such economies, but I find important extensions.

First, I look at economies with consumption at two times, and I examine the effect of the risk-free rate on asset pricing. I find that a non-zero risk-free rate leads to non-zero prices of tax payments. Even though not traded, prices of tax payments can be constructed from tradeable assets. For a zero risk-free rate capital gains taxes and the respective transfer payments have a zero (implicit) price. I construct two economies that have agents with equal endowments with shares of financial assets and consumption goods, equal utility functions and payoffs. I impose a tax on capital gains on one economy. I show that, for any tax economy, there is a no-tax economy with equal prices. This holds for two economies in which individual consumption of agents in one economy is the same as the consumption in the other economy in every state. Then, the stochastic discount factor in the no-tax economy of any agent is the same as in the tax economy. Since taxes are not priced this leads to the same asset prices in both economies. Furthermore, I obtain the same portfolio rule as in Kruschwitz and Löffler (2009). This rule makes consumption profiles of investors equal in both economies with a zero risk-free rate. It follows that this rule is not just applicable to mean-variance CAPM economies but also to economies with expected utility maximizing agents, and in which a risk-free asset is traded and has a zero return. Without a zero risk-free rate price equality does not generally hold. For linear marginal utility it can be shown that it never holds.

I also regard the case of economies with consumption only in the future. In this case the risk-free rate is exogenous. For a zero risk-free rate price equality can be obtained again. For a non-zero risk-free rate, I show that exponential utility and multivariate normal payoffs lead to a pair of economies with equal prices. It is only necessary to pick equal prices of the risk-free assets in both economies. In contrast to Kruschwitz and Löffler (2009), who use mean-variance utility arguments, I use SDF arguments to derive this result. Furthermore, I show that aggregate wealth after initial consumption in the no-tax economy is different to the one in the tax economies - even though prices are the same. In the tax economy aggregate wealth is different from wealth in the no-tax economy by the price of aggregate transfer payments, which do not have zero prices as with a zero risk-free rate. The portfolio rule for risky assets is again the same as the one proposed in Kruschwitz and Löffler (2009). However, the rule for the risk-free asset differs. Furthermore, I find that utility functions that lead to marginal utility linear in consumption also lead to price equality. The reason here is that individual pricing equations can easily be 
aggregated to a pricing equation that does not depend on the tax rate. With nonlinear marginal utility prices cannot generally be obtained since aggregation regularly does not lead to a pricing equation that is independent from the tax rate.

I contribute to the asset pricing literature that is especially concerned with tax effects on asset pricing. Much of the literature is concerned with the classic meanvariance CAPM such as Kruschwitz and Löffler (2009) and Eikseth and Lindset (2009), who consider tax transfers back to the investors. Sialm (2006), in turn, uses a representative agent model with an uncertain tax on consumption and tax transfers. He finds that aggregate consumption and therefore marginal utility growth is not affected when all taxes are transferred back. With certain and constant taxes there would not be an effect on asset prices versus no taxes. Brennan (1970) is a classic paper that incorporates various personal tax rates into the CAPM to arrive at pre-tax expected returns, but it does not consider transfers. Wiese (2007) builds on Brennan's work to develop a model that reflects the German tax code. I especially include SDF and consumption arguments into my analysis in the fashion of Cochrane (2014).

In Sect. 2, I introduce the basic economy without taxes and the economy with a flat and certain tax rate on capital gains. In the following Sect. 3, I show that for every no-tax economy there is a tax economy with equal asset prices in the cases when the risk-free rate is zero. When consumption only takes place in the future and therefore the risk-free rate is exogenous, equal prices are obtained when agents have exponential utility with normal consumption or when they have linear marginal utility. I continue to discuss the results and the limitations of the analyses in Sect. 4, where I also provide a simple numerical example. I conclude in Sect. 5.

\section{The two basic economies}

\subsection{The basic finance economy without taxes}

Payoff space I model an endowment economy with financial assets. The economy exists at dates $t=0$, when decisions are made and initial consumption takes place, and at $t=1$, when payoffs are paid out and consumed. I add to the model of Kruschwitz and Löffler (2009) consumption at $t=0$. I denote $\mathbf{X}_{r}$ as an $N \times S$ matrix of tradeable, risky and elementary payoffs, in which $N$ is the number of payoffs and $S$ the number of possible states at $t=1$. With elementary or basic payoffs, I mean non-redundant payoffs. Non-redundant, in turn, means that any single elementary payoff cannot be constructed through linear combinations of other payoffs. This matrix is augmented by a risk-free payoff $X_{0}$, which is also non-redundant, so that, $\mathbf{X}=\left(\begin{array}{ll}X_{0} & \mathbf{X}_{r}\end{array}\right)^{\prime}$ is an $N+1 \times S$ matrix of non-redundant payoffs. Thus, the payoff space is spanned by $N$ elementary risky asset payoffs and a risk-free payoff. The number of states $S$ can be greater than the number of assets so that an incomplete market is possible. I use the subscript $s$ for individual states and the subscript $j$ for the different financial assets so that the payoff $j$ pays $X_{j s}$ in state $s$. To simplify notation, I put time subscripts only when necessary, such as for consumption, which 
is possible at $t=0$ and at $t=1$. I use all random variables as row vectors of dimension $1 \times S$. Constants such as prices of a single asset $j$, denoted $p_{j}$, can also be written as a $1 \times S$ vector of constant values.

Characterization of the agents and their maximization problems There are $i=$ $1, \ldots, I$ agents in the economy. Agents are rational and have the same complete set of information, i.e., they know the distributions of the payoffs. They are characterized through a time separable utility function $u_{i}(\cdot)$ over consumption and through initial (pre-trade) portfolio holdings $\overline{\mathbf{n}}_{i}$. At date $t=1$ and in state $s$ agent $i$ consumes $c_{i s}$ units of a composite consumption good. One unit of a consumption good has a price of one at all times so that a payoff of one can buy exactly one unit of the consumption good. To address random variables such as agent $i$ 's consumption or the $j$ 'th payoff at $t=1$, I leave out the subscript $s$ for states and write $c_{i 1}$ and $X_{j}$, respectively. I denote $\bar{c}_{i 0}$ the endowment of agent $i$ with consumption goods at time $t=0$.

Agents maximize expected utility of consumption,

$$
\max _{c_{i 0}, c_{i 1}} E\left[\beta_{i} u_{i}\left(c_{i 1}\right)\right]+u_{i}\left(c_{i 0}\right),
$$

subject to the budget constraints at $t=0$,

$$
\overline{\mathbf{n}}_{i}^{\prime} \mathbf{p}+\bar{c}_{i 0}=\mathbf{n}_{i}^{\prime} \mathbf{p}+c_{i 0}
$$

and at $t=1$

$$
c_{i s}=\mathbf{n}_{i}^{\prime} \mathbf{X}_{s}
$$

for $s=1, \ldots, S$. I use all collections of prices and asset weights as column vectors. I denote $E[\cdot]$ the expected value at time zero of its argument, $\mathbf{p}=$ $\left(p_{0} p_{1} \cdots p_{j} \cdots p_{N}\right)^{\prime}$ is the price vector of the $N+1$ assets, $\mathbf{n}_{i}=$ $\left(n_{i 0} n_{i 1} \cdots n_{i j} \cdots n_{i N}\right)^{\prime}$ is a vector of after-trade portfolio weights (I use $\overline{\mathbf{n}}_{i}$ for pretrade portfolios.), $\beta_{i}$ the subjective time discount factor (or impatience factor), and $u_{i}(\cdot)$ the utility function. The expected value operator with a single random variable means a probability inner product. With a random variable $z$ that means $E[z]=\sum_{s=1}^{S} \pi_{s} z_{s}$, in which $\pi_{s}$ is the probability of state $s$. For prices I mostly use the short notation so that $p_{j}$ is the price of a payoff $X_{j}$. When necessary, I also use prices as operators to make more clear what is priced, for example $p_{j}=p\left(X_{j}\right)$ is again the price of the payoff $j$. Furthermore, I use the subscript $r$ to refer only to the risky assets $\mathbf{p}_{r}=\left(p_{1} \cdots p_{j} \cdots p_{N}\right)^{\prime}$ and $\mathbf{n}_{i r}=\left(n_{i 1} \cdots n_{i j} \cdots n_{i N}\right)^{\prime}$, the subscript zero is related to the risk-free asset. ${ }^{1}$ The utility function is differentiable and strictly monotonously increasing at a decreasing rate. Therefore, any additional unit of consumption adds to utility, and it is optimal to consume all of the payoffs, which justifies to write the budget constraints as equalities (Lengwiler 2004, p. 52). The equality of the budget constraints allows to substitute out consumption and to restate the maximization problem with respect to the portfolio weights and initial consumption.

\footnotetext{
${ }^{1}$ Without too much abuse of notation, I also use the subscript zero for consumption at $t=0$.
} 
The risk-free asset is in zero net supply $\sum_{i=1}^{I} n_{i 0}=0$. Therefore, I define a vector of aggregate asset holdings $\mathbf{n}=\sum_{i=1}^{I} \mathbf{n}_{i}$, which is $\mathbf{n}^{\prime}=\left(\begin{array}{lllll}0 & 1 & 1 & \cdots & 1\end{array}\right)$ because the risk-free asset is in zero net supply.

Equilibrium The equilibrium is given through a vector of prices $\mathbf{p}$, consumption profiles $c_{i 0}, c_{i 1}$ and portfolios $\mathbf{n}_{i}$ for $i=1, \ldots, I$ so that each agent maximizes utility subject to his budget constraint, given prices p. Furthermore, the market for the consumption good clears: $\sum_{i=1}^{I} \bar{c}_{i 0}=\sum_{i=1}^{I} c_{i 0}$ and $\sum_{i=1}^{I} c_{i s}=\mathbf{n}^{\prime} \mathbf{X}_{s}$ for $s=1, \ldots, S$. Financial assets are in positive net supply and markets clear so that $\sum_{i=1}^{I} n_{i j}=$ $\sum_{i=1}^{I} \bar{n}_{i j}=1$ for $j=1, \ldots, N$ and $\sum_{i=1}^{I} n_{i 0}=0$ for the risk-free asset. I assume that at least one equilibrium exists. Notice that equilibrium prices imply the absence of arbitrage opportunities (Lengwiler 2004, p.50).

Pricing equations I write the agent's optimization problem in terms of a Lagrangian:

$$
\mathcal{L}_{i}=E\left[\beta_{i} u_{i}\left(c_{i 1}\right)\right]+u_{i}\left(c_{i 0}\right)-\lambda_{i}\left(\mathbf{n}_{i}^{\prime} \mathbf{p}+c_{i 0}-\overline{\mathbf{n}}_{i}^{\prime} \mathbf{p}-\bar{c}_{i 0}\right),
$$

where $\lambda_{i}$ is a Lagrange multiplier. I substitute in Eq. (3) and take the partial derivatives with respect to portfolio weights and to initial consumption. Combining the results I obtain,

$$
\mathbf{p}=E\left[\mathbf{X} \beta_{i} \frac{u_{i}^{\prime}\left(c_{i 1}\right)}{u_{i}^{\prime}\left(c_{i 0}\right)}\right]
$$

I denote more compactly,

$$
m_{i}=\beta_{i} \frac{u_{i}^{\prime}\left(c_{i 1}\right)}{u_{i}^{\prime}\left(c_{i 0}\right)}
$$

as agent $i$ 's stochastic discount factor (SDF). Using this, I can price any single payoff $X_{j}$ through:

$$
p_{j}=E\left[m_{i} X_{j}\right]
$$

Here the expected value means that probabilities are induced to the inner product of $X_{j}$ and $m_{i}: E\left[m_{i} X_{j}\right]=\sum_{s=1}^{S} \pi_{s} m_{i} X_{j s}$. Through trading, agents find a price vector on which everyone agrees, i.e., $\mathbf{p}=E\left[m_{i} \mathbf{X}\right]$ for $i=1, \ldots, I$, and which maximizes utility.

In complete markets, $\mathbf{X}$ is a square matrix with full rank, i.e., there are as many basic assets as states. The equation $\mathbf{p}=E\left[m_{i} \mathbf{X}\right]$ can be written as: $\mathbf{p}=\mathbf{X} \kappa_{i}$, in which state prices are: $\kappa_{i s}=m_{i s} \pi_{s}$ for $s=1, \ldots, S$ and $\pi_{s}$ are objective probabilities of states $s$. When $\mathbf{X}$ has full rank, there is a unique solution for $\kappa_{i}$. Since probabilities are objective probabilities, there is a unique SDF, i.e., every agent has the same SDF. It also follows that the state price vector can be expressed as a linear combination of basis assets and therefore lies in the payoff space. The same is true for the $\mathrm{SDF}^{2}$

\footnotetext{
${ }^{2}$ For properties of the SDF under different assumptions such as market incompleteness, see (Cochrane 2005, pp. 61-73).
} 
With incomplete markets, i.e., with $S>N+1, \mathbf{X}$ does not have full rank. The system of equations $\mathbf{p}=\mathbf{X} \kappa_{i}$ has less equations than unknowns so that there is more than one solution to the system. That means state prices and SDFs among agents may differ.

Pricing a risk-free payoff of one, I define the risk-free rate as $R_{\mathrm{f}}=1 / E\left[m_{i}\right]=$ $1 / p_{0}$ for $i=1, \ldots, I$. The term $R_{\mathrm{f}}$ is the gross risk-free rate: $R_{\mathrm{f}}=1+r_{\mathrm{f}}$. Thus, the pricing Eq. (7) can be restated as:

$$
p_{j}=\frac{E\left(X_{j}\right)}{R_{\mathrm{f}}}+\operatorname{Cov}\left(m_{i}, X_{j}\right),
$$

in which $\operatorname{Cov}\left(m_{i}, X_{j}\right)$ is the covariance between the SDF and the payoff. As stated in Cochrane (2014), in incomplete markets the SDFs of agents $m_{i}$ can differ and do not have to be within the payoff space. But there is one SDF $m$ within the space of tradeable assets that prices all assets. This SDF is the probability induced projection of all of the agents' SDFs onto the payoff space. The relation between the unique SDF within the payoff space and any individual SDF is $m_{i}=m+\epsilon_{i}$, where $\epsilon_{i}$ is an error term orthogonal to the (probability induced) payoff space and therefore does not influence prices: $p_{j}=E\left(m_{i} X_{j}\right)=E\left(\left(m+\epsilon_{i}\right) X_{j}\right)=E\left(m X_{j}\right)$, because $E\left(\epsilon_{i} X_{j}\right)=0$ holds for all payoffs of the payoff space (Cochrane 2005, p. 66). The unique SDF within the payoff space can be used to price all payoffs but it will not necessarily lead to a possible portfolio rule for all agents, i.e., to a consumption profile that is within the payoff space. In complete markets the SDF is the same for every agent. In the standard CAPM, which does not require complete markets, the SDF is a linear combination of the market return: $m=a+b R^{M}$, where $R^{M}$ is the return on the market portfolio and $a$ and $b$ are constants (Cochrane 2005, p. 152). In those two cases the single SDF leads straightforwardly to consumption rules within the payoff space.

\subsection{The finance economy with taxes}

I introduce another economy that has, compared to the no-tax economy, equal utility functions of agents $u_{i}(\cdot)$, equal impatience factors $\beta_{i}$, and an equal (pre-tax) distribution of payoffs of financial assets $\mathbf{X}$. The initial or pre-trade portfolios of agents with shares of assets are also the same, as well as the agents' perfect information about the payoff distributions. I introduce taxes on capital gains. To account for possible differences in prices, after-trade portfolios, and consumption profiles from the ones in the no-tax economy, I add an asterisk to them. Prices of taxed payoffs are denoted as, $p_{j}^{* \tau}=p^{*}\left(X_{j}^{\tau}\right)$ and prices of pre-tax payoffs are denoted as, $p_{j}^{*}=p^{*}\left(X_{j}\right)$.

Taxes I define the tax base as the difference between the payoff and the price of the payoff: $X_{j s}-p_{j}^{* \tau}$, in which $p_{j}^{* \tau}$ is the price of the after-tax payoff, i.e., of the payoff $X_{j s}^{\tau}=X_{j s}-T_{j s}=X_{j s}-\tau\left(X_{j s}-p_{j}^{* \tau}\right)$, in which $T_{j s}$ are taxes on the asset $j=$ $0,1, \ldots, N$ in states $s=1, \ldots, S$. Any observed prices reflect possible tax effects. Investors consider the taxes they have to pay on the payoff when pricing the asset. I use $\tau \in(0,1)$ as the tax rate and also as a superscript to denote after-tax 
figures when necessary. The tax rate is certain, constant, and the same for all agents. This is a simplification since tax rates can be observed to have an uncertain element and they often depend on certain characteristics of agents such is their income. ${ }^{3}$ Introducing an uncertain tax rate may introduce an additional covariance as well as an expectation into the pricing equation. An agent $i$ pays capital gains taxes at the amount $T_{i s}=\tau \sum_{j=0}^{N} n_{i j}^{*}\left(X_{j s}-p_{j}^{* \tau}\right)=\tau \mathbf{n}_{i}^{* \prime}\left(\mathbf{X}_{s}-\mathbf{p}^{* \tau}\right)$, and they receive transfer payments $Q_{i s}=\tau \omega_{i} \mathbf{n}^{\prime}\left(\mathbf{X}_{s}-\mathbf{p}^{* \tau}\right)$ for $i=1, \ldots, I$, in which $\omega_{i}$ is the share of total tax revenues that is transferred to agent $i$ with $\sum_{i=1}^{I} \omega_{i}=1$. Transfer payments are predetermined amounts, i.e., they cannot be influenced by the agents. Positive and negative capital gains are taxed the same way. I discuss issues of this simplified tax system versus more realistic tax systems in Sect. 4. Aggregate tax payments are $T_{s}=\sum_{i=1}^{I} T_{i s}$. They must be equal to aggregate transfer payments: $T_{s}=Q_{s}$. Individual transfer payments can also be written as $Q_{i s}=\omega_{i} T_{s}{ }^{4}$

The introduction of taxes and transfers does not introduce any new basic asset so that the payoff space is the same as in the no-tax economy. Any tax payment $T_{j s}=X_{j s}-\tau\left(X_{j s}-p_{j}^{* \tau}\right)=X_{j s}(1-\tau)+\tau p_{j}^{* \tau}$ is just a linear combination of the pretax payoff $X_{j}$ and a risk-free payoff.

Characterization of the agents and their maximization problems Any agent maximizes expected utility of after-tax (and transfers) consumption,

$$
\max _{c_{i 0}^{*}, c_{i 1}^{*}} E\left[u_{i}\left(c_{i 1}^{*}\right)\right]+u_{i}\left(c_{i 0}^{*}\right)
$$

subject to the budget constraints at $t=0$

$$
\overline{\mathbf{n}}_{i}^{\prime} \mathbf{p}^{* \tau}+\bar{c}_{i 0}=\mathbf{n}_{i}^{* \prime} \mathbf{p}^{* \tau}+c_{i 0}^{*}
$$

and at $t=1$

$$
c_{i s}^{*}=\mathbf{n}_{i}^{* \prime}\left(\mathbf{X}_{s}-\tau\left(\mathbf{X}_{s}-\mathbf{p}^{* \tau}\right)\right)+Q_{i s},
$$

for $s=1, \ldots, S$. The variable $\mathbf{n}_{i}^{*}$ is a vector of after-trade portfolio weights. I denote financial wealth that is left after initial consumption as $W_{i}^{* F \tau}=\mathbf{n}_{i}^{* \prime} \mathbf{p}^{* \tau}$ and total financial wealth after initial consumption, i.e., financial wealth including transfers as $W_{i}^{* F}=W_{i}^{* F \tau}+p^{*}\left(Q_{i}\right)$.

Equilibrium The equilibrium is given through a vector of prices $\mathbf{p}^{* \tau}$, consumption profiles $c_{i 0}^{*}, c_{i 1}^{*}$ and portfolios $\mathbf{n}_{i}^{*}$ for $i=1, \ldots, I$ so that each agent maximizes utility subject to his budget constraint, given prices $\mathbf{p}^{* \tau}$. Furthermore, the market for the consumption good clears: $\sum_{i=1}^{I} \bar{c}_{i 0}=\sum_{i=1}^{I} c_{i 0}^{*}$ and $\sum_{i=1}^{I} c_{i s}^{*}=\mathbf{n}^{* \prime} \mathbf{X}_{s} \quad$ for $s=1, \ldots, S$. That this holds comes from the fact that taxes are just redistributions

\footnotetext{
3 See for example Sialm (2006) for a theoretical treatment of tax rate uncertainty on asset prices and Sialm (2009) for an econometric treatment.

4 A case when agents receive transfers exactly at the amount they pay taxes is when $T_{i s}=Q_{i s}$ or $\tau \mathbf{n}_{i}^{* \prime}\left(\mathbf{X}_{s}-\mathbf{p}^{* \tau}\right)=\tau \omega_{i} \mathbf{n}^{\prime}\left(\mathbf{X}_{s}-\mathbf{p}^{* \tau}\right)$. This implies $\left(\mathbf{n}_{i}^{* \prime}-\omega_{i} \mathbf{n}^{\prime}\right)\left(\mathbf{X}_{s}-\mathbf{p}^{* \tau}\right)=0$. Since $\left(\mathbf{X}_{s}-\mathbf{p}^{* \tau}\right)$ includes risky assets, it cannot be a zero matrix. The vector $\mathbf{n}_{i}^{* \prime}-\omega_{i} \mathbf{n}^{\prime}$ is a vector of zeros for $\mathbf{n}_{i}^{* \prime}=\omega_{i} \mathbf{n}^{\prime}$, which is a very special case. With the risk-free asset in zero net supply this requires the first element of $\mathbf{n}_{i}^{*}$ be zero and all of the remaining elements be equal to the constant $\omega_{i}$. If the risk-free asset is in positive net supply, all elements of $\mathbf{n}_{i}^{*}$ must be equal to $\omega_{i}$.
} 
and do not change aggregate values. Financial assets are in positive net supply and clear so that $\sum_{i=1}^{I} n_{i j}^{*}=\sum_{i=1}^{I} \bar{n}_{i j}=1$ for $j=1, \ldots, N$, and $\sum_{i=1}^{I} n_{i 0}^{*}=0$ for the riskfree asset.

Pricing equations The first-order conditions lead to a similar pricing equation as for the no-tax economy, except that after-tax payoffs are priced:

$$
p_{j}^{* \tau}=E\left[m_{i}^{*} X_{j}^{\tau}\right] .
$$

The after-tax risk-free payoff is $X_{0}^{\tau}=X_{0}-\tau\left(X_{0}-p_{0}^{* \tau}\right)=1-\tau\left(1-p_{0}^{* \tau}\right)$, and the after-tax risk-free rate is:

$$
R_{\mathrm{f}}^{* \tau}=\frac{1-\tau\left(1-p_{0}^{* \tau}\right)}{E\left[m_{i}^{*}\left(1-\tau\left(1-p_{0}^{* \tau}\right)\right)\right]}=\frac{1}{E\left[m_{i}^{*}\right]}=\frac{1-\tau\left(1-p_{0}^{* \tau}\right)}{p_{0}^{* \tau}} .
$$

The second equality follows from the fact that $1-\tau\left(1-p_{0}^{* \tau}\right)$ is a constant, which can be taken out of the expectations in the denominator and therefore cancels with the term in the numerator. The third equality just restates that the denominator is actually the price of the cash flow $X_{0}^{\tau}=1-\tau\left(1-p_{0}^{* \tau}\right)$. The pre-tax risk-free rate is then,

$$
R_{\mathrm{f}}^{*}=\frac{1}{E\left[m_{i}^{*}\left(1-\tau\left(1-p_{0}^{* \tau}\right)\right)\right]}=\frac{1}{p_{0}^{* \tau}} .
$$

Using $R_{\mathrm{f}}^{*}=1 / p_{0}^{* \tau}$ the after-tax return can also be written as $R_{\mathrm{f}}^{* \tau}=1+r_{\mathrm{f}}^{*}(1-\tau)$. If the risk-free rate is not taxed, it is $R_{\mathrm{f}}^{*}=1 / E\left[m_{i}^{*}\right]$. Notice that since the risk-free asset is traded, every agent agrees upon the risk-free rate. It follows that the expected individual SDFs must be equal, which, in turn, are equal to the expected SDF within the payoff space: $E\left[m^{*}\right]=E\left[m_{i}^{*}\right]$ for $i=1, \ldots, I$.

In an economy with capital gains taxes, the expectations of the SDFs $E\left[m_{i}^{*}\right]$ play a special role. This is summarized in the following proposition:

Proposition 1 Assume an asset $j$ with a pre-tax payoff $X_{j}$, and with an after-tax payoff $X_{j}^{\tau}$ with positive prices. Capital gains are taxed at a certain tax rate $\tau \in(0,1)$. Assume further that $1 / E\left[m_{i}^{*}\right]>\tau$. The prices of the pre-tax payoff $p_{j}^{*}$ and of the after-tax payoff $p_{j}^{* \tau}$ are only equal as long as $E\left[m_{i}^{*}\right]=1$ for $i=1, \ldots, I$. With $E\left[m_{i}^{*}\right]$ greater (less) than one the price of the after-tax payoff $p_{j}^{* \tau}$ is greater (less) than the price of the pre-tax payoff $p_{j}^{*}$.

Proof After tax payoffs are defined as $X_{j}^{\tau}=(1-\tau) X_{j}+\tau p_{j}^{* \tau}$. The respective price of this payoff is:

$$
\begin{aligned}
p_{j}^{* \tau} & =E\left[m_{i}^{*} X_{j}^{\tau}\right]=E\left[m_{i}^{*}\left((1-\tau) X_{j}+\tau p_{j}^{* \tau}\right)\right] \\
& =(1-\tau) E\left[m_{i}^{*} X_{j}\right]+\tau p_{j}^{* \tau} E\left[m_{i}^{*}\right] .
\end{aligned}
$$

This can be rewritten as: 


$$
p_{j}^{* \tau}=p_{j}^{*}(1-\tau)+\tau p_{j}^{* \tau} E\left[m_{i}^{*}\right]
$$

which can be rearranged to:

$$
p_{j}^{* \tau}=\frac{p_{j}^{*}(1-\tau)}{1-\tau E\left[m_{i}^{*}\right]} .
$$

Thus, when $E\left[m_{i}^{*}\right]=1$, the tax terms cancel and prices of the pre-tax payoff and the one of the after-tax payoff are the same. In any other case the prices are not the same. Equation (17) shows further that for $E\left[m_{i}^{*}\right]>1$, it follows that $(1-\tau) /(1-$ $\left.\tau E\left[m_{i}^{*}\right]\right)>1$ so that $p_{j}^{* \tau}>p_{j}^{*}$ and vice versa. Equation (17) also shows that, given $E\left[m_{i}^{*}\right]$, i.e., the price of a payoff of one in every state, one can derive prices of pretax from after-tax payoffs and vice versa. The condition $1 / E\left[m_{i}^{*}\right]>\tau$ ensures that the denominator of Equation (17) is positive.

I assume that $1 / E\left[m_{i}^{*}\right]>\tau$ holds throughout the paper.

Notice that those pre-tax-after-tax price relations use an SDF of the tax economy $m_{i}^{*}$. Any relations to the SDFs of the no-tax economy, i.e., to $m_{i}$, are still to be obtained.

Notice also that $E\left[m_{i}^{*}\right]=1$ implies that $E\left[\frac{u_{i}^{\prime}\left(c_{i 1}^{*}\right)}{u_{i}^{\prime}\left(c_{i 0}^{*}\right)}\right]=1 / \beta_{i}$. Expected growth of marginal utility of consumption is exactly equal to the inverse of the impatience factor. Higher growth implies a lower risk-free rate and lower growth a higher one. A simple log-normal model such as in (Cochrane 2005, pp. 10-12) allows for more interpretations of the risk-free rate in terms of consumption growth. In this case the risk-free rate is low when expected consumption growth is low or impatience is low, i.e., when beta is high.

The prior proposition has several implications.

Corollary 1 When the risk-free rate is not taxed, then, according to Eq. (13), $R_{\mathrm{f}}^{*}=1 / E\left[m_{i}^{*}\right]$, and it follows that $E\left[m_{i}^{*}\right]=1$ and $r_{\mathrm{f}}^{*}=0$ are equivalent for all $i=1, \ldots, I$. Furthermore, $E\left[m_{i}^{*}\right]$ greater (less) than one is equivalent with the riskfree rate $r_{\mathrm{f}}^{*}$ being less (greater) than zero.

Corollary 2 When the risk-free rate is taxed, then, according to Eq. (13), $R_{\mathrm{f}}^{* \tau}=1 / E\left[m_{i}^{*}\right]$, and $E\left[m_{i}^{*}\right]=1$ and $r_{\mathrm{f}}^{* \tau}=0$ are equivalent for all $i=1, \ldots, I$. Furthermore, $E\left[m_{i}^{*}\right]$ greater (less) than 1 is equivalent with the after-tax risk-free rate $r_{\mathrm{f}}^{* \tau}$ being less (greater) than zero.

Corollary 3 In the case of a zero risk-free rate, the tax on capital gains has a zero price. From the above proposition follows that pre-and after-tax prices are the same, i.e., $p_{j}^{* \tau}=p_{j}^{*}-p^{*}\left(T_{j}\right)=p_{j}^{*}$, so that $p^{*}\left(T_{j}\right)=0$. Furthermore, whether the risk-free rate of return is taxed as well does not matter when it is zero because taxes on that asset would also be zero.

In the following section, I continue to analyze equilibrium effects, i.e., how taxes affect prices and quantities in the no-tax and the tax economy. 


\section{Asset prices and portfolios in the no-tax and the tax economy}

\subsection{General conditions for price equality}

I use the endowment economies, the one without and one with a tax on capital gains, that I have outlined in the prior section. I explore the general conditions under which prices are the same in the two economies. ${ }^{5}$

I continue to state the general conditions for asset prices be equal. I start with individual pricing equations and then continue with aggregate pricing equations and projections.

\subsubsection{Individual pricing equations}

Proposition 2 Asset prices in the no-tax and in the tax economy are equal, i.e., $\mathbf{p}=\mathbf{p}^{* \tau}$, if and only if:

$$
E\left[m_{i} \mathbf{X}\right]=E\left[m_{i}^{*} \mathbf{X} \frac{R_{\mathrm{f}}^{* \tau}}{R_{\mathrm{f}}^{*}}\right],
$$

for $i=1, \ldots, I$.

Proof I start with the vector of after-tax prices. Similar to the derivation of Eq. (17) for a single price, the price vector is given by:

$$
\begin{aligned}
\mathbf{p}^{* \tau} & =E\left[m_{i}^{*} \mathbf{X}^{\tau}\right]=E\left[m_{i}^{*}\left((1-\tau) \mathbf{X}^{\tau}+\tau \mathbf{p}^{* \tau}\right)\right] \\
& =(1-\tau) E\left[m_{i}^{*} \mathbf{X}\right]+\tau \mathbf{p}^{* \tau} E\left[m_{i}^{*}\right] .
\end{aligned}
$$

This can be rearranged to,

$$
\mathbf{p}^{* \tau}=\frac{1-\tau}{1-\tau E\left[m_{i}^{*}\right]} E\left[m_{i}^{*} \mathbf{X}\right] .
$$

From Eq. (13) we know that $R_{\mathrm{f}}^{* \tau}=1 / E\left[m_{i}^{*}\right]$. Substituting that into the prior equation I obtain:

$$
\mathbf{p}^{* \tau}=\frac{1-\tau}{1-\tau / R_{\mathrm{f}}^{* \tau}} E\left[m_{i}^{*} \mathbf{X}\right] .
$$

I multiply the numerator and the denominator by $R_{\mathrm{f}}^{* \tau}$, which yields:

$$
\mathbf{p}^{* \tau}=\frac{R_{\mathrm{f}}^{* \tau}(1-\tau)}{R_{\mathrm{f}}^{* \tau}-\tau} E\left[m_{i}^{*} \mathbf{X}\right] .
$$

The denominator is $R_{\mathrm{f}}^{* \tau}-\tau=1+r_{\mathrm{f}}^{*}(1-\tau)-\tau=(1-\tau)+r_{\mathrm{f}}^{*}(1-\tau)=$ $R_{\mathrm{f}}^{*}(1-\tau)$, so that the $1-\tau$ terms cancel. This leads to:

\footnotetext{
5 Notice that price equality concerns the tradeable financial assets. Transfer payments are not tradeable and do not belong to financial assets.
} 


$$
\mathbf{p}^{* \tau}=E\left[m_{i}^{*} \mathbf{X} \frac{R_{\mathrm{f}}^{* \tau}}{R_{\mathrm{f}}^{*}}\right],
$$

which I set equal to $\mathbf{p}=E\left[m_{i} \mathbf{X}\right]$ to obtain the condition in the proposition.

Corollary 4 From Eq. (14), i.e., from the fact that $R_{\mathrm{f}}^{*}=1 / p_{0}^{* \tau}$, and from $R_{\mathrm{f}}=$ $1 / p_{0}$ as well as from price equality of the risk-free assets follows that the risk-free rate in the no-tax economy is equal to the pre-tax risk-free rate in the tax economy: $R_{\mathrm{f}}=R_{\mathrm{f}}^{*}$. Furthermore, $R_{\mathrm{f}}=R_{\mathrm{f}}^{*}$ implies $E\left[m_{i}\right]=E\left[m_{i}^{*}\right]$ and vice versa, which follows from the definition of the risk-free rates.

For example from a pre-tax risk-free gross rate of return greater one, i.e., $R_{\mathrm{f}}^{*}>1$, follows that the after-tax rate is less than the pre-tax rate: $R_{\mathrm{f}}^{* \tau}<R_{\mathrm{f}}^{*}=R_{\mathrm{f}}$. After accounting for taxes, agents would require less return than they would in the no-tax economy. They value a unit payoff more than in the no-tax economy. For a zero risk-free rate pre- and after-tax rates are the same so that the valuation of a unit payoff would not change.

Corollary 5 Equation (18) can also be rewritten in terms of covariances:

$$
\frac{E[\mathbf{X}]}{R_{\mathrm{f}}}+\operatorname{Cov}\left(m_{i}, \mathbf{X}\right)=\frac{E[\mathbf{X}]}{R_{\mathrm{f}}^{*}}+\operatorname{Cov}\left(m_{i}^{*}, \mathbf{X}\right) \frac{R_{\mathrm{f}}^{* \tau}}{R_{\mathrm{f}}^{*}} .
$$

With $R_{\mathrm{f}}=R_{\mathrm{f}}^{*}$ from Corollary 4, I simplify to obtain:

$$
\operatorname{Cov}\left(m_{i}, \mathbf{X}\right)=\operatorname{Cov}\left(m_{i}^{*}, \mathbf{X}\right) \frac{R_{\mathrm{f}}^{* \tau}}{R_{\mathrm{f}}^{*}},
$$

for $i=1, \ldots, I$.

Furthermore, Proposition 2 implies a condition that guarantees that the proposition holds.

Corollary 6 The relation of the individual SDFs

$$
m_{i}^{*} \frac{R_{\mathrm{f}}^{* \tau}}{R_{\mathrm{f}}^{*}}=m_{i}
$$

for $i=1, \ldots, I$ is sufficient to obtain price equality for all assets.

This relation constitutes a strong assumption in that the SDF of any agent in the tax economy is proportional to the SDF of an equal agent in the no-tax economy in every state. I assume the agents' preferences to be the same in both economies so that a comparison makes sense. That means the agents' individual impatience factors and the parameters and functional form of their utility functions are the same. That also means it is consumption at $t=0$ and consumption in the different states at $t=1$ that determine the SDFs and possible differences in the SDFs of the two economies. Equation (26) can be restated as:

$$
u_{i}^{\prime}\left(c_{i 1}\right)=\zeta u_{i}^{\prime}\left(c_{i 1}^{*}\right),
$$

in which $\zeta=u_{i}^{\prime}\left(c_{i 0}\right) / u_{i}^{\prime}\left(c_{i 0}^{*}\right) R_{\mathrm{f}}^{* \tau} / R_{\mathrm{f}}^{*}$ is a constant that collects the ratio of the riskfree rates and the first derivatives of the utility functions of consumption at $t=0$. 
This relation shows that Eq. (26) implies that marginal utility at $t=1$ be proportional.

With a zero risk-free rate the condition in Eq. (18) simplifies to,

$$
E\left[m_{i} \mathbf{X}\right]=E\left[m_{i}^{*} \mathbf{X}\right]
$$

and $m_{i}^{*}=m_{i}$ is sufficient to fulfill this condition, which is the same as condition (26) for a zero risk-free rate. Notice that the above conditions are derived from the price equations, which, in turn, are the rearranged first order conditions, i.e., the optimality conditions, of the agents. Thus making those equations hold guarantees optimality. Together they form an aggregate pricing equation.

\subsubsection{Aggregate pricing equation}

To obtain an aggregate demand function, I sum the individual equations of the form $\mathbf{p}^{* \tau} u_{i}^{\prime}\left(c_{i 0}^{*}\right)=E\left[\beta_{i} u_{i}^{\prime}\left(c_{i 1}^{*}\right) \mathbf{X}_{r}^{\tau}\right]$ over all agents. Rearranging for prices I obtain:

$$
\mathbf{p}^{* \tau}=E\left[\frac{\sum_{i=1}^{I} \beta_{i} u_{i}^{\prime}\left(c_{i 1}^{*}\right) \mathbf{X}_{r}^{\tau}}{\sum_{i=1}^{I} u_{i}^{\prime}\left(c_{i 0}^{*}\right)}\right] .
$$

The aggregate SDF is then:

$$
m^{a *}=\frac{\sum_{i=1}^{I} \beta_{i} u_{i}^{\prime}\left(c_{i 1}^{*}\right)}{\sum_{i=1}^{I} u_{i}^{\prime}\left(c_{i 0}^{*}\right)} .
$$

This aggregate SDF prices all assets just as good as the individual SDFs. Given utility functions, it may help to find an aggregate pricing function.

Consumption, be it individual or aggregate, must lie within the payoff space. Even with taxes, when there are non-tradeable transfer payments, those payments can be replicated by tradeable payments because they are linear functions of tradeable payments. If marginal utility is linear in consumption, the quadratic utility case, all individual SDFs must lie within the payoff space. Since there can only be one SDF within the payoff space, all individual SDFs must be the same. Furthermore, it is well-known that this SDF can be written as a linear function in terms of aggregate consumption $c_{0}$ and $c_{1}$, when all agents have the same time discount factor. Appendix B shows a derivation. I come back to this important special case later.

\subsubsection{Projections of SDFs}

As pointed out in Sect. 2.1, there is a unique SDF within the payoff space that prices all assets, and which is related to the individual SDFs through $m=m_{i}+\epsilon_{i}$, with $\epsilon_{i}$ being an error term orthogonal to the probability induced payoff space (for the tax economy with an asterisk, respectively).

Proposition 3 Asset prices in the no-tax and in the tax economy are equal, i.e., $\mathbf{p}=\mathbf{p}^{* \tau}$, if and only if: 


$$
E[m \mathbf{X}]=E\left[m^{*} \mathbf{X} \frac{R_{\mathrm{f}}^{* \tau}}{R_{\mathrm{f}}^{*}}\right],
$$

in which $m$ and $m^{*}$ are the SDFs in the payoff space in the no-tax and the tax economy, respectively.

Proof I use the relations $m=m_{i}+\epsilon_{i}$ and $m^{*}=m_{i}^{*}+\epsilon_{i}^{*}$ with errors orthogonal to the probability induced payoff space, i.e., $E\left[\epsilon_{i} \mathbf{X}\right]=0$ and $E\left[\epsilon_{i}^{*} \mathbf{X}^{\tau}\right]=0$ for all $i$. The price vector of the tax economy is:

$$
\begin{aligned}
\mathbf{p}^{* \tau} & =E\left[m_{i}^{*} \mathbf{X}^{\tau}\right]=E\left[\left(m^{*}-\epsilon_{i}^{*}\right) \mathbf{X}^{\tau}\right] \\
& =E\left[m^{*} \mathbf{X}^{\tau}\right]-E\left[\epsilon_{i}^{*} \mathbf{X}^{\tau}\right] \\
& =E\left[m^{*} \mathbf{X}^{\tau}\right] .
\end{aligned}
$$

The term $E\left[\epsilon_{i}^{*} \mathbf{X}^{\tau}\right]$ is zero since the error term is orthogonal to the payoff space. For the no-tax economy the derivation is similar. The remainder is similar to the proof of Proposition 2.

Since the error terms do not affect the pricing of the assets, the corollaries follow just as before.

Corollary 7 Corollaries 4-6 also follow for the SDF within the payoff space, i.e., for $m$ and $m^{*}$.

\subsubsection{Budget constraints and market clearing}

So far I have found a necessary and sufficient condition for price equality in Proposition 2 and a sufficient condition in Corollary 6. For an actual equilibrium allocation, budget constraints have to be met and markets need to clear as well. In the following, a tax and an equivalent no-tax economy will compared, which are in equilibrium. Thus, apart from meeting conditions of price equality the budget constraints and market clearing need to hold, so that this step is also included in the following analyses.

I will continue as follows: under the assumptions that the no-tax economy is in equilibrium, I will derive sufficient conditions for the existence of a tax equilibrium with prices equal to the ones in the no-tax economy. To do that, I will draw on the conditions established herein.

\subsection{Economies with consumption at $t=0$ and $t=1$}

\subsubsection{A zero risk-free rate and equal consumptions in both economies}

In the following I will show that, with a zero risk-free rate, for an equilibrium in the no-tax economy there exists an equilibrium in the tax economy in which agents circumvent redistribution through the capital gains tax and through the transfer payments using the same portfolio rule as in Kruschwitz and Löffler (2009). As 
Kruschwitz and Löffler (2009) point out, equilibria need not be unique so that other equilibria may exist that are not consistent with such an allocation.

From the prior section it is obvious that with a zero risk-free rate $R_{\mathrm{f}}^{* \tau} / R_{\mathrm{f}}^{*}=1$. Then, the equality $m_{i}^{*}=m_{i}$ for $i=1, \ldots, I$ is sufficient to obtain price equality, since Corollary 6 is met. Since consumption at the different dates is the only variable argument in the SDFs of the agents, it is clear that equal consumption of agents in both economies leads to equal SDFs. This follows from observation of Eq. (27).

It remains to show that there is a portfolio rule that makes equal consumption possible. Budget constraints have to hold and markets have to clear. I show that the portfolio rule that ensures equal consumption is the same as the one in Kruschwitz and Löffler (2009).

Before I turn to the portfolio rule, I will make some remarks. With equal individual SDFs, i.e., with $m_{i}^{*}=m_{i}$ for $i=1, \ldots, I$, and with a zero risk-free rate, which makes prices of taxes and transfers zero, asset prices in both economies must be the same and pre-tax prices are equal to after-tax prices: $\mathbf{p}=\mathbf{p}^{* \tau}=\mathbf{p}^{*}$. Asset prices in the tax economy are $\mathbf{p}^{* \tau}=E\left[m_{i}^{*} \mathbf{X}^{\tau}\right]=E\left[m_{i}^{*}(\mathbf{X}-\mathbf{T})\right]$. Using this and noting that $E\left[m_{i} \mathbf{T}\right]=0$, it follows that $\mathbf{p}^{* \tau}=E\left[m_{i}^{*} \mathbf{X}^{\tau}\right]=E\left[m_{i}^{*}(\mathbf{X}-\mathbf{T})\right]=$ $E\left[m_{i} \mathbf{X}\right]=\mathbf{p}$. With equal initial portfolios equal prices imply that agents have the same financial wealth after initial consumption in both economies: $W_{i}^{F}=W_{i}^{* F \tau}=W_{i}^{* F}$.

Agents receive the same utility as in the no-tax economy. With a zero price of taxes the initial budget constraints of the agents are also equal to the ones of the notax economy. Thus, agents maximize utility and obey their budget constraints.

I continue to construct the portfolio rule so that consumption is equal in both economies and that markets clear. With equal initial portfolios and wealth, i.e., agents have the same initial characteristics in both economies, equal consumption means that an optimum in the no-tax economy is equivalent to an optimum in the tax economy.

Initial consumption is just a constant, which is set equal for any agent in both economies. Consumption at $t=1$ needs more attention.

Proposition 4 Given equal prices in the tax and the no tax economy, consumptions at $t=1$ of all agents $i=1, \ldots, I$ are the same in both economies if and only if risky portfolios of all agents $i$ for the no-tax and the tax economy are related through

$$
\mathbf{n}_{i r}=\mathbf{n}_{r i}^{*}(1-\tau)+\omega_{i} \tau \mathbf{n}_{r},
$$

and weights on the risk-free assets are related through

$$
n_{0 i}=n_{0 i}^{*}(1-\tau)+\tau\left(W_{i}^{F}-\omega_{i} W^{F}\right) .
$$

Proof Consumption of any agent $i$ at $t=1$ in the no-tax economy is simply $c_{i 1}=\mathbf{n}_{i}^{\prime} \mathbf{X}$. Consumption in the tax economy is; 


$$
c_{i 1}^{*}=\mathbf{n}_{i}^{* \prime}(\mathbf{X}-\tau(\mathbf{X}-\mathbf{p}))+\omega_{i} \tau \mathbf{n}^{\prime}(\mathbf{X}-\mathbf{p}) .
$$

I use the no-tax price notation because, $\mathbf{p}=\mathbf{p}^{* \tau}$ must hold for the portfolios that are implied. Every investor consumes the same in both economies if $c_{i 1}=c_{i 1}^{*}$ or

$$
\mathbf{n}_{i}^{\prime} \mathbf{X}=\mathbf{n}_{i}^{* \prime}(\mathbf{X}-\tau(\mathbf{X}-\mathbf{p}))+\omega_{i} \tau \mathbf{n}^{\prime}(\mathbf{X}-\mathbf{p}) .
$$

Since $W_{i}^{F}=\mathbf{n}_{i}^{* \prime} \mathbf{p}$ and $W^{F}=\mathbf{n}^{\prime} \mathbf{p}$, I restate the equation as:

$$
\mathbf{n}_{i}^{\prime} \mathbf{X}=\mathbf{n}_{i}^{* \prime}(1-\tau) \mathbf{X}+\tau W_{i}^{F}+\omega_{i} \tau \mathbf{n}^{\prime} \mathbf{X}-\omega_{i} \tau W^{F} .
$$

For complete markets given $\mathbf{n}_{i}^{*}$ there is a unique solution for $\mathbf{n}_{i}$ since $\mathbf{X}$ is a square matrix of full rank. For incomplete markets the system of equations is overdetermined, i.e., a system with more equations (number of states) than unknowns (number of portfolio weights). Overdetermined systems need not have a perfect solution at all. ${ }^{6}$ However in this case there is a unique perfect solution, which will be verified below. I separate into risky and constant parts, which leads to:

$$
n_{i 0}+\mathbf{n}_{i r}^{\prime} \mathbf{X}_{r}=n_{i 0}^{* \prime}(1-\tau)+\tau W_{i}^{F}-\omega_{i} \tau W^{F}+\left(\mathbf{n}_{i r}^{* \prime}(1-\tau)+\omega_{i} \tau \mathbf{n}_{r}^{\prime}\right) \mathbf{X}_{r} .
$$

Now, simple observation shows that,

$$
\mathbf{n}_{i r}^{\prime}=\mathbf{n}_{i r}^{* \prime}(1-\tau)+\tau \omega_{i} \mathbf{n}_{r}^{\prime},
$$

in which the vector $\mathbf{n}_{r}^{\prime}$ is the same as $\mathbf{n}^{\prime}$ without the first element, i.e., a vector of ones, and

$$
n_{i 0}=n_{i 0}^{*}(1-\tau)+\tau\left(W_{i}^{F}-\omega_{i} W^{F}\right)
$$

is a solution to the system of equations. Systems of linear equations can have zero, one or infinitely many solutions. I found that there is at least one solution to this system of linear equations. It is also exactly one since the payoffs in the matrix $\mathbf{X}$ are linearly independent, so that infinitely many solutions are not possible.

This is the same relation of shares of risky assets that Kruschwitz and Löffler (2009) propose for the mean-variance CAPM with taxes on capital gains, with transfers, and with a zero risk-free rate, to obtain equilibria at equal prices in a tax and a no-tax economy. Since I do not assume any specific utility function that would imply the mean-variance CAPM, I conclude that their proposition for portfolio weights is not limited to the mean-variance CAPM.

In the CAPM, I can further simplify because every investor holds the market portfolio ${ }^{7}$ so that all elements within the vectors $\mathbf{n}_{i r}$ and $\mathbf{n}_{i r}^{*}$ are equal, i.e., $n_{i 1}=$ $n_{i 2}=\cdots=n_{i j}=\cdots=n_{i N}$ and $n_{i 1}^{*}=n_{i 2}^{*}=\cdots=n_{i j}^{*}=\cdots=n_{i N}^{*}$.

\footnotetext{
6 One can still obtain an approximate solution in the least squares sense (see also Williams 1990).

7 Kruschwitz and Husmann (2012, pp. 186-189) present the Tobin Separation Theorem together with the Mutual Fund Theorem, which state that every investor holds a share of the market portfolio and of the risk-free asset.
} 


\subsubsection{The case of linear marginal utility}

A special case is marginal utility linear in consumption of all agents, i.e., something like $u_{i}^{\prime}\left(c_{i 1}\right)=a_{i}+b_{i} c_{i 1}$, and equal time discount factors $\beta=\beta_{i}$ for all $i$. Then, all individual SDFs are equal and lie within the payoff space. With equal time discount factors, the SDF depends on aggregate consumption in $t=0$ and $t=1$ and some constants (see Appendix B). In equilibrium agents consume all what they have since it is optimal to do that. Aggregate consumption must be the same in the no-tax and the tax economy, because agents are given the same endowments, and pre-tax payoffs are the same. Thus, for linear marginal utility and equal time discount factors the $\mathrm{SDF}(\mathrm{s})$ are the same in the no-tax and the tax economy. Given zero riskfree rates, asset prices must be the same as well. An example of this case for quadratic utility is given in Sect. 4.2.1. Furthermore, with equal SDFs in both economies, if the risk-free rate is not zero, there is no price equality, because Proposition 2 does not hold anymore. ${ }^{8}$

\subsection{Economies with consumption only at $t=1$}

\subsubsection{General remarks}

I continue to look at economies that have no time zero consumption. Kruschwitz and Löffler (2009) limit their analysis to this kind of economies. In this case the risk-free rate is assumed to be exogenous to the economy. It is not the result of the trade-off of current and future consumption as in the model with consumption at $t=0$ and at $t=1$, because consumption at $t=0$ does not take place. ${ }^{9}$ I also simplify to assume that all of the agents have a time discount factor of 1 .

An agent's maximization problem is:

$$
\max _{c_{i 1}^{*}} E\left[u_{i}\left(c_{i 1}^{*}\right)\right],
$$

subject to the budget constraints at $t=0$

$$
\bar{n}_{i 0} p_{0}^{* \tau}+\overline{\mathbf{n}}_{i r}^{\prime} \mathbf{p}_{r}^{* \tau}=n_{i 0}^{*} p_{0}^{* \tau}+\mathbf{n}_{i r}^{* \prime} \mathbf{p}_{r}^{* \tau}
$$

and at $t=1$

$$
c_{i 1}^{*}=n_{i 0}^{*}\left(X_{0}-\tau\left(X_{0}-p_{0}^{* \tau}\right)\right)+\mathbf{n}_{i r}^{* \prime}\left(\mathbf{X}_{r}-\tau\left(\mathbf{X}_{r}-\mathbf{p}_{r}^{* \tau}\right)\right)+\omega_{i} \tau \mathbf{n}_{r}^{\prime}\left(\mathbf{X}_{r}-\mathbf{p}_{r}^{* \tau}\right) .
$$

As in Kruschwitz and Löffler (2009), I rearrange the time zero budget constraint for the quantity of the risky asset to obtain:

\footnotetext{
${ }^{8}$ With $m=m^{*}$, in which I leave out the subscript since all individual SDFs are the same, the equation in Proposition 2 turns into $E[m \mathbf{X}]=E\left[m \mathbf{X}_{\frac{\mathrm{f}}{R_{\mathrm{f}}^{*}}}^{R_{*}^{*}}\right.$, a statement which is not true for non-zero $r_{\mathrm{f}}^{*}$.

9 The definitions in terms of prices of a pre- or after tax cash flow of one still hold: $R_{\mathrm{f}}^{* \tau}=\frac{1-\tau\left(1-p_{0}^{* \tau}\right)}{p_{0}^{* \tau}}$ and $R_{\mathrm{f}}^{*}=\frac{1}{p_{0}^{* \tau} \text {. }}$
} 


$$
n_{i 0}^{*}=1 / p_{0}^{* \tau}\left(\bar{n}_{i 0} p_{0}^{* \tau}+\overline{\mathbf{n}}_{i r}^{\prime} \mathbf{p}_{r}^{* \tau}-\mathbf{n}_{i r}^{* \prime} \mathbf{p}_{r}^{* \tau}\right)
$$

and substitute this expression into the one for consumption and solve the maximization problem to obtain:

$$
E\left[u_{i}^{\prime}\left(c_{i}^{*}\right)\left(\left(X_{0}(1-\tau)+\tau p_{0}^{* \tau}\right) \mathbf{p}_{r}^{* \tau} / p_{0}^{* \tau}(-1)+\mathbf{X}_{r}(1-\tau)+\tau \mathbf{p}_{r}^{* \tau}\right)\right]=0 .
$$

The equation can be restated as:

$$
E\left[u_{i}^{\prime}\left(c_{i}^{*}\right)\left(\mathbf{X}_{r}^{\tau}-\mathbf{p}_{r}^{* \tau} R_{\mathrm{f}}^{* \tau}\right)\right]=0
$$

so that rearrangement leads to,

$$
\mathbf{p}_{r}^{* \tau}=\frac{E\left[u_{i}^{\prime}\left(c_{i}^{*}\right) \mathbf{X}_{r}^{\tau}\right]}{R_{\mathrm{f}}^{* \tau} E\left[u_{i}^{\prime}\left(c_{i}^{*}\right)\right]},
$$

with the SDFs $m_{i}^{*}=\frac{u_{i}^{\prime}\left(c_{i}^{*}\right)}{R_{\mathrm{f}}^{* \tau} E\left[u_{i}^{\prime}\left(c_{i}^{*}\right)\right]}$. An apparent question is whether and in which cases $c_{i}=c_{i}^{*}$ for all $i$ would lead to price equality. In this case the SDFs can be rewritten as $m_{i}^{*}=\frac{u_{i}^{\prime}\left(c_{i}\right)}{R_{\mathrm{f}}^{* \tau} E\left[u_{i}^{\prime}\left(c_{i}\right)\right]}$. Multiplying by $R_{\mathrm{f}}^{* \tau} / R_{\mathrm{f}}^{*}$ gives $m_{i}^{*} \frac{R_{\mathrm{f}}^{* \tau}}{R_{\mathrm{f}}^{*}}=\frac{u_{i}^{\prime}\left(c_{i}\right)}{R_{\mathrm{f}}^{*} E\left[u_{i}^{\prime}\left(c_{i}\right)\right]}$. SDFs in the notax economy are $m_{i}=\frac{u_{i}^{\prime}\left(c_{i}\right)}{R_{\mathrm{f}} E\left[u_{i}^{\prime}\left(c_{i}\right)\right]}$. Since the risk-free rate is exogenous, I set $R_{\mathrm{f}}^{*}=R_{\mathrm{f}}$, i.e., $p_{0}^{* \tau}=p_{0}$ as it is done in Kruschwitz and Löffler (2009). Now the condition in Eq. (26) holds and prices must be equal. Notice that with consumption only at $t=1$, equal consumption does not lead to equal SDFs, but rather to proportional SDFs.

However, in equilibrium, the budget constraints have to hold as well. If and only if the portfolio rules derived in the prior part hold, will there be equal consumptions in both economies. It turns out that this only holds for a zero risk-free rate. To show this, I start with the budget constraint in the no-tax economy denoted as in Eq. (43), and I substitute in Eq. (32). This leads to,

$$
n_{0 i}=\bar{n}_{0 i}+\left(\overline{\mathbf{n}}_{i r}^{\prime}-\mathbf{n}_{i r}^{* \prime}(1-\tau)+\omega_{i} \tau \mathbf{n}_{r}^{\prime}\right) \frac{\mathbf{p}_{r}}{p_{0}}
$$

Now, I use the budget constraint $n_{0 i}^{*}=\bar{n}_{0 i}+\left(\mathbf{n}_{i r}^{* \prime}-\overline{\mathbf{n}}_{i r}^{\prime}\right) \mathbf{p}_{r} / p_{0}$ rearranged to $\bar{n}_{0 i}=$ $n_{0 i}^{*}-\left(\mathbf{n}_{i r}^{* \prime}-\overline{\mathbf{n}}_{i r}^{\prime}\right) \mathbf{p}_{r} / p_{0}$ and $W^{F}=\mathbf{n}_{r}^{\prime} \mathbf{p}_{r}$ and substitute both into the prior equation, which leads to,

$$
\begin{aligned}
n_{0 i} & =n_{0 i}^{*}+\tau\left(\mathbf{n}_{i r}^{* \prime} \mathbf{p}_{r}-\omega_{i} W^{F}\right) \frac{1}{p_{0}} \\
& =n_{0 i}^{*}(1-\tau)+\tau\left(W_{i}^{F}-\omega_{i} W^{F}\right) \frac{1}{p_{0}} .
\end{aligned}
$$

Notice that this is different from Eq. (33) when $p_{0}$ is not 1, i.e., when the risk-free rate is not zero. Thus, portfolio rules consistent with equal consumptions of agents cannot be obtained when prices are equal in both economies.

Even though this path is closed, there are some cases when price equality can be obtained. However, consumptions are not equal anymore. Notice that for a zero 
risk-free rate the equal consumption approach still leads to price equality the same way as in the model with initial consumption.

\subsubsection{Multivariate normal payoffs and exponential utility}

If the risk-free rate is not zero, condition (18) has to hold to make prices in the notax and the tax economy equal. Kruschwitz and Löffler (2009) discover that for the CAPM with constant absolute risk aversion (CARA), for every no-tax economy there is a tax economy with equal prices. They use arguments from a mean-variance utility approach. I use exponential utility, which is a CARA utility, and normal consumption, which lead to the CAPM (Cochrane 2005, pp. 154-155), and SDF arguments to derive the result that CARA utility together with multivariate normal payoffs works to obtain for every no-tax economy a tax economy with the same prices. I will keep the risk-free asset in zero net supply. With multivariate normal payoffs, I have to relax the assumption of a finite and discrete payoff space.

I use exponential utility of the form:

$$
u_{i}\left(c_{i}\right)=-\frac{\exp \left(-\alpha_{i} c_{i}\right)}{\alpha_{i}},
$$

in which $\alpha_{i}>0$ is agent $i$ 's coefficient of absolute risk aversion.

Consumption is a linear combination of multivariate normal payoffs so that consumption is normal as well. Therefore, I rewrite the expected value in the maximization condition as:

$$
E\left[u_{i}\left(c_{i 1}^{*}\right)\right]=-\frac{\exp \left(-\alpha_{i} E\left[c_{i 1}^{*}\right]+0.5 \alpha_{i}^{2} \operatorname{Var}\left(c_{i 1}^{*}\right)\right)}{\alpha_{i}},
$$

with the budget constraints as in Eqs. (41) and (42). I maximize with respect to asset weights to obtain the first-order conditions. For risky assets I obtain:

$$
\begin{aligned}
(1-\tau) E\left[\mathbf{X}_{r}\right] & +\tau \mathbf{p}_{r}^{* \tau}-\mathbf{p}_{r}^{* \tau} \frac{X_{0}-\tau\left(X_{0}-p_{0}^{* \tau}\right)}{p_{0}^{* \tau}} \\
& -\alpha_{i}(1-\tau) \Omega\left((1-\tau) \mathbf{n}_{r i}^{*}+\omega_{i} \tau \mathbf{n}_{r}\right)=0,
\end{aligned}
$$

in which $\Omega$ is the covariance matrix of the payoffs of risky assets. Using $R_{\mathrm{f}}^{* \tau}=$ $\frac{X_{0}-\tau\left(X_{0}-p_{0}^{* \tau}\right)}{p_{0}^{* \tau}}$ and cancelling the $1-\tau$ terms leads to,

$$
E\left[\mathbf{X}_{r}\right]-\mathbf{p}_{r}^{* \tau} R_{\mathrm{f}}^{*}-\alpha_{i} \Omega\left((1-\tau) \mathbf{n}_{r i}^{*}+\omega_{i} \tau \mathbf{n}_{r}\right)=0,
$$

which can be rearranged for portfolio weights,

$$
\mathbf{n}_{r i}^{*}=\frac{1}{1-\tau}\left(\frac{1}{\alpha_{i}} \Omega^{-1}\left(E\left[\mathbf{X}_{r}\right]-\mathbf{p}_{r}^{* \tau} R_{\mathrm{f}}^{*}\right)-\omega_{i} \tau \mathbf{n}_{r}\right) .
$$

The equation shows that individual portfolio weights depend on the tax rate $\tau$, the coefficient of absolute risk aversion $\alpha_{i}$, and the share in transfer payments $\omega_{i}$. Rearranging and summing Eq. (53) over all agents leads to, 


$$
\left(E\left[\mathbf{X}_{r}\right]-\mathbf{p}_{r}^{* \tau} R_{\mathrm{f}}^{*}\right) \sum_{i=1}^{I} \frac{1}{\alpha_{i}}=\Omega \mathbf{n}_{r} .
$$

This is the same as Equation (26) in Kruschwitz and Löffler (2009) when $-\sum_{i=1}^{I} \frac{2}{\alpha_{i}}=\sum_{i=1}^{I} \frac{U_{i E[c]}}{U_{i \mathrm{Var}(c)}}$ holds, in which $U_{i E[c]}$ is the derivative of a mean-variance utility function with respect to the expected value of consumption and $U_{i \operatorname{Var}(c)}$ is the first derivative of a mean-variance utility function with respect to the variance of consumption. ${ }^{10}$ Notice that Eq. (51) is a mean-variance utility function. The derivatives with respect to the expected value and the variance of consumption are $U_{i E[c]}=\exp \left(-\alpha_{i} E\left[c_{i 1}^{*}\right]+0.5 \alpha_{i}^{2} \operatorname{Var}\left(c_{i 1}^{*}\right)\right) \quad$ and $\quad U_{i \operatorname{Var}(c)}=-\exp \left(-\alpha_{i} E\left[c_{i 1}^{*}\right]+\right.$ $\left.0.5 \alpha_{i}^{2} \operatorname{Var}\left(c_{i 1}^{*}\right)\right) 0.5 \alpha_{i}$. It follows that $\frac{U_{i E[c]}}{U_{i \operatorname{Var}(c)}}=-\frac{2}{\alpha_{i}}$. Summing this expression over agents shows that $-\sum_{i=1}^{I} \frac{2}{\alpha_{i}}=\sum_{i=1}^{I} \frac{U_{i E[C]}}{U_{i \mathrm{Var}(c)}}$ holds. It turns out that the ratio $\frac{U_{i E[c]}}{U_{i \mathrm{Var}(c)}}$ only depends on the coefficient of absolute risk aversion $\alpha_{i}$. Notice that Kruschwitz and Löffler (2009) state that this ratio depends on the individual agents' variances of consumption and that this is also stated in Meyer (1987) and Lajeri-Chaherli and Nielsen (1993). However in those two sources the ratios presented are a bit different in that the denominator uses the derivative of the mean-variance utility function with respect to standard deviation, i.e., $\frac{U_{i E[c]}}{U_{i S \mathrm{St}(c)}}$, in which $\operatorname{Std}(\cdot)$ stands for standard deviation. For the case at hand this derivative yields $U_{i \operatorname{Std}(c)}=$ $-\exp \left(-\alpha_{i} E\left[c_{i 1}^{*}\right]+0.5 \alpha_{i}^{2} \operatorname{Var}\left(c_{i 1}^{*}\right)\right) \operatorname{Std}\left(c_{i 1}^{*}\right) \alpha_{i}$. It follows that $\frac{U_{i E[c]}}{U_{i S \mathrm{Std}(c)}}=-\frac{1}{\operatorname{Std}\left(c_{i 1}^{*}\right) \alpha_{i}}$, which actually does depend on the standard deviation of consumption.

It turns out that for exponential utility with multivariate normal payoffs, capital gains taxes under the tax system described herein do not influence asset prices at all. As Eq. (55) shows, all of the tax terms and dependencies on the tax rate disappear in the aggregate pricing equation. That leads to the following proposition:

Proposition 5 In the tax-economy set up above, in which agents have exponential utility and in which consumption only takes place at $t=1$, the product $\mathbf{p}_{r}^{* \tau} R_{\mathrm{f}}^{*}$, i.e., the ratio $\mathbf{p}_{r}^{* \tau} / p_{0}^{* \tau}$, does not depend on the tax rate. Furthermore, the corresponding no-tax economy will have the same product as the tax-economy $\mathbf{p}_{r}^{* \tau} R_{\mathrm{f}}^{*}=\mathbf{p}_{r} R_{\mathrm{f}}$, i.e., the same ratio $\mathbf{p}_{r}^{* \tau} / p_{0}^{* \tau}=\mathbf{p}_{r} / p_{0}$.

Proof I rearrange Eq. (55) to

$$
\mathbf{p}_{r}^{* \tau} R_{\mathrm{f}}^{*}=E\left[\mathbf{X}_{r}\right]-\frac{\Omega \mathbf{n}_{r}}{\sum_{i=1}^{I} \frac{1}{\alpha_{i}}} .
$$

The rhs of this equation is exactly the same for the no-tax economy. The same rhs for both economies must lead to the same lhs.

\footnotetext{
${ }^{10}$ There is a minor typo in Equations (25) and (26) in Kruschwitz and Löffler (2009). In Equation (25) the mathematical sign in front of the variance term should be positive as in Equations (13) and (16). Equation (26) has to be adjusted accordingly.
} 
Notice that the relation $\mathbf{p}_{r}^{* \tau} R_{\mathrm{f}}^{*}=\mathbf{p}_{r} R_{\mathrm{f}}$ just follows from the model. However, price equality is only there if the $R_{\mathrm{f}}^{*}=R_{\mathrm{f}}$. Otherwise, prices would only be proportional but not equal. Since consumption takes place only at $t=1$ the risk-free rate does not say something about the trade-off of consumption today versus consumption tomorrow. It is exogenous to the economy and will be chosen so that prices of risk-free assets are equal.

Corollary 8 Asset prices are equal in the tax and the no-tax economy set up above, with exponential utility, multivariate normal payoffs and with consumption only at $t=1$, when $R_{\mathrm{f}}^{*}=R_{\mathrm{f}}$, i.e., when $p_{0}^{* \tau}=p_{0}$.

Proposition 6 Given equilibrium prices, risky portfolios of all agents $i$ for the notax and the tax economy are related through,

$$
\mathbf{n}_{i r}=\mathbf{n}_{r i}^{*}(1-\tau)+\omega_{i} \tau \mathbf{n}_{r},
$$

and risk-free weights are related through,

$$
n_{0 i}=n_{0 i}^{*}(1-\tau)+\tau\left(W_{i}^{F}-\omega_{i} W^{F}\right) \frac{1}{p_{0}} .
$$

Proof Equation (54) for a zero tax rate shows that the equation for the no-tax case is,

$$
\mathbf{n}_{r i}=\frac{1}{\alpha_{i}} \Omega^{-1}\left(E\left[\mathbf{X}_{r}\right]-\mathbf{p}_{r} R_{\mathrm{f}}\right) .
$$

Regarding the tax case, Eq. (54) can be rearranged to,

$$
\mathbf{n}_{r i}^{*}(1-\tau)+\omega_{i} \tau \mathbf{n}_{r}=\frac{1}{\alpha_{i}} \Omega^{-1}\left(E\left[\mathbf{X}_{r}\right]-\mathbf{p}_{r}^{* \tau} R_{\mathrm{f}}^{*}\right) .
$$

From Proposition 5 we know that $\mathbf{p}_{r}^{* \tau} R_{\mathrm{f}}^{*}=\mathbf{p}_{r} R_{\mathrm{f}}$, and it follows that the rhs of Eqs. (59) and (60) are equal. Thus, the lhs of the two equations are equal as well.

For the weight on the risk-free asset, I use the budget constraint of Eq. (43) but for the no-tax economy, and I substitute in Eq. (32). This leads to,

$$
n_{0 i}=\bar{n}_{0 i}+\left(\overline{\mathbf{n}}_{i r}^{\prime}-\mathbf{n}_{r i}^{* \prime}(1-\tau)-\omega_{i} \tau \mathbf{n}_{r}^{\prime}\right) \frac{\mathbf{p}_{r}}{p_{0}}
$$

I use the relations $\bar{n}_{0 i}+\overline{\mathbf{n}}_{i r}^{\prime} \mathbf{p}_{r} / p_{0}=W_{i}^{F} / p_{0}$ and $W^{F}=\mathbf{n}_{r}^{\prime} \mathbf{p}_{r}$ and substitute both into the prior equation, which leads to:

$$
n_{0 i}=W_{i}^{F} \frac{1}{p_{0}}-\mathbf{n}_{r i}^{* \prime}(1-\tau) \frac{\mathbf{p}_{r}}{p_{0}}-\omega_{i} \tau W^{F} \frac{1}{p_{0}}
$$

Now, I add a constructive zero in the form of $n_{0 i}^{*}(1-\tau) p_{0} / p_{0}-n_{0 i}^{*}(1-\tau)$ and rearrange to obtain the weight on the risk-free asset from the proposition,

$$
n_{0 i}=n_{0 i}^{*}(1-\tau)+\tau\left(W_{i}^{F}-\omega_{i} W^{F}\right) \frac{1}{p_{0}} .
$$


The portfolio rule for risky assets is the same as for the case with the zero riskfree rate and equal consumption and it is the same as the one presented in Kruschwitz and Löffler (2009) for the constant absolute risk aversion case. Different from Kruschwitz and Löffler (2009) I find that one only needs equal prices of the risk-free assets and price equality of risky assets follow. The weight on the risk-free assets is now different from the one presented before (Eq. 33) in that the price of the risk-free asset appears in the equation. That means individual consumptions of agents are not equal in the no-tax and the tax economy. The budget constraints are used in constructing portfolio rules and the resulting portfolio rules sum over agents to one for risky assets and to zero for the risk-free assets. It follows that budget constraints are met and markets clear.

From Eq. (26) we know that $m_{i}^{*} \frac{R_{\mathrm{f}}^{* \tau}}{R_{\mathrm{f}}^{*}}=m_{i}$ is a sufficient condition to obtain price equality for the tax and the no-tax economy. However, the converse does not have to be true. There may be other relations of SDFs that also lead to price equality. However, under the specifications made in this section price equality also leads to $m_{i}^{*} \frac{R_{\mathrm{f}}^{* \tau}}{R_{\mathrm{f}}^{*}}=m_{i}$.

Proposition 7 For the type of economy set up herein, given equality of prices of a tax and a no-tax economy, the condition in Eq. (26) holds.

Proof To use the SDF language I use the budget constraint (43) in the consumption part of Eq. (40) and take derivatives with respect to $\mathbf{n}_{i r}^{*}$. I obtain: $\mathbf{0}=E\left[u_{i}^{\prime}\left(c_{i 1}^{*}\right)\left(\mathbf{X}_{r}^{\tau}-R_{\mathrm{f}}^{* \tau} \mathbf{p}_{r}^{* \tau}\right)\right]$. I rearrange the expression to,

$$
\mathbf{p}_{r}^{* \tau}=E\left[\frac{u_{i}^{\prime}\left(c_{i 1}^{*}\right)}{R_{\mathrm{f}}^{* \tau} E\left[u_{i}^{\prime}\left(c_{i 1}^{*}\right)\right]} \mathbf{X}_{r}^{\tau}\right],
$$

in which $m_{i}^{*}=\frac{u_{i}^{\prime}\left(c_{i 1}^{*}\right)}{R_{\mathrm{f}}^{* \tau} E\left[u_{i}^{\prime}\left(c_{i 1}^{*}\right)\right]}$ is the stochastic discount factor. Without taxes the SDF is $m_{i}=\frac{u_{i}^{\prime}\left(c_{i 1}\right)}{R_{\mathrm{f}} E\left[u_{i}^{\prime}\left(c_{i 1}\right)\right]}$. I start with the SDFs of the tax economy and rewrite them to obtain:

$$
\begin{aligned}
m_{i}^{*} & =\frac{u_{i}^{\prime}\left(c_{i 1}^{*}\right)}{R_{\mathrm{f}}^{* \tau} E\left[u_{i}^{\prime}\left(c_{i 1}^{*}\right)\right]} \\
& =\frac{\exp \left(-\alpha_{i} c_{i 1}^{*}\right)}{R_{\mathrm{f}}^{* \tau} E\left[\exp \left(-\alpha_{i} c_{i 1}^{*}\right)\right]} \\
& =\frac{\exp \left(-\alpha_{i} c_{i 1}^{*}\right)}{R_{\mathrm{f}}^{* \tau} \exp \left(-\alpha_{i} E\left[c_{i 1}^{*}\right]+0.5 \alpha_{i}^{2} \operatorname{Var}\left(c_{i 1}^{*}\right)\right)} .
\end{aligned}
$$

The second equality uses the first derivative of the utility function (50) with respect to consumption. The third equality uses the fact that consumption is normally distributed. Consumption from Eq. (42) consists of a risky part $c_{i 1 r}^{*}$ and a risk-free part $\quad c_{i 1 f}^{*}: \quad c_{i 1}^{*}=c_{i 1 r}^{*}+c_{i 1 f}^{*}, \quad$ in $\quad$ which $\quad c_{i 1 r}^{*}=\left(\mathbf{n}_{i r}^{* \prime}(1-\tau)+\omega_{i} \tau \mathbf{n}_{r}^{\prime}\right) \mathbf{X}_{r} \quad$ and $c_{i 1 f}^{*}=n_{0}^{*}\left(X_{0}-\tau\left(X_{0}-p_{0}^{* \tau}\right)\right)+\tau \mathbf{n}_{i r}^{* \prime} \mathbf{p}_{r}^{* \tau}-\omega_{i} \tau \mathbf{n}_{r}^{\prime} \mathbf{p}_{r}^{* \tau}$. From Eq. (32) we know that the risky part of consumption in the tax and the no-tax economy are equal for any agent: $c_{i 1 r}^{*}=c_{i 1 r}$. That also means that $\operatorname{Var}\left(c_{i 1}^{*}\right)=\operatorname{Var}\left(c_{i 1}\right)$. Using that I rewrite the SDF to 


$$
\begin{aligned}
m_{i}^{*} & =\frac{\exp \left(-\alpha_{i} c_{i 1 r}\right) \exp \left(-\alpha_{i} c_{i 1 f}^{*}\right)}{R_{\mathrm{f}}^{* \tau} \exp \left(-\alpha_{i} E\left[c_{i 1 r}\right]\right) \exp \left(-\alpha_{i} E\left[c_{i 1 f}^{*}\right]\right) \exp \left(0.5 \alpha_{i}^{2} \operatorname{Var}\left(c_{i 1}\right)\right)} \\
& =\frac{\exp \left(-\alpha_{i} c_{i 1 r}\right)}{R_{\mathrm{f}}^{* \tau} \exp \left(-\alpha_{i} E\left[c_{i 1 r}\right]\right) \exp \left(0.5 \alpha_{i}^{2} \operatorname{Var}\left(c_{i 1}\right)\right)} .
\end{aligned}
$$

In the second equality the $\exp \left(-\alpha_{i} E\left[c_{i 1 f}^{*}\right]\right)$ terms cancel out. That leads to,

$$
\frac{R_{\mathrm{f}}^{* \tau}}{R_{\mathrm{f}}^{*}} m_{i}^{*}=\frac{\exp \left(-\alpha_{i} c_{i 1 r}\right)}{R_{\mathrm{f}}^{*} \exp \left(-\alpha_{i} E\left[c_{i 1 r}\right]\right) \exp \left(0.5 \alpha_{i}^{2} \operatorname{Var}\left(c_{i 1}\right)\right)} .
$$

The SDF of the no-tax economy can be written as:

$$
\begin{aligned}
m_{i} & =\frac{u_{i}^{\prime}\left(c_{i 1}\right)}{R_{\mathrm{f}} E\left[u_{i}^{\prime}\left(c_{i 1}\right)\right]} \\
& =\frac{\exp \left(-\alpha_{i} c_{i 1}\right)}{R_{\mathrm{f}} E\left[\exp \left(-\alpha_{i} c_{i 1}\right)\right]} \\
& =\frac{\exp \left(-\alpha_{i} c_{i 1}\right)}{R_{\mathrm{f}} \exp \left(-\alpha_{i} E\left[c_{i 1}\right]+0.5 \alpha_{i}^{2} \operatorname{Var}\left(c_{i 1}\right)\right)} \\
& =\frac{\exp \left(-\alpha_{i} c_{i 1 r}\right) \exp \left(-\alpha_{i} c_{i 1 f}\right)}{R_{\mathrm{f}} \exp \left(-\alpha_{i} E\left[c_{i 1 r}\right]\right) \exp \left(-\alpha_{i} E\left[c_{i 1 f}\right]\right) \exp \left(0.5 \alpha_{i}^{2} \operatorname{Var}\left(c_{i 1}\right)\right)} \\
& =\frac{\exp \left(-\alpha_{i} c_{i 1 r}\right)}{R_{\mathrm{f}} \exp \left(-\alpha_{i} E\left[c_{i 1 r}\right]\right) \exp \left(0.5 \alpha_{i}^{2} \operatorname{Var}\left(c_{i 1}\right)\right)} .
\end{aligned}
$$

With price equality $R_{\mathrm{f}}=R_{\mathrm{f}}^{*}$ so that Eq. (68) is equal to Eq. (67).

Some remarks on wealth are appropriate. It turns out that aggregate consumptions are the same in both economies because aggregate payoffs are the same. However, individual consumptions differ as was noted before. Consumption is also valued differently so that wealth differs between the economies. For example an agent $i$ would value aggregate wealth as follows:

$$
W^{* F}=E\left(m_{i}^{*} c_{1}\right)=E\left(m_{i} c_{1}\right) \frac{R_{\mathrm{f}}^{*}}{R_{\mathrm{f}}^{* \tau}}=W^{F} \frac{R_{\mathrm{f}}^{*}}{R_{\mathrm{f}}^{* \tau}} .
$$

Equation (69) shows that, with a positive risk-free rate, wealth in the tax economy is greater than in the no-tax economy. Individually, equal initial portfolio holdings and price equality imply that the values of the pre-trade portfolios are the same in the tax-economy and the no-tax economy:

$$
\overline{\mathbf{n}}_{i}^{\prime} \mathbf{p}^{* \tau}=\overline{\mathbf{n}}_{i}^{\prime} \mathbf{p} .
$$

The increased aggregate wealth in the tax economy is due to transfer payments. I price the sum of the after-tax portfolio payoff $\mathbf{n}_{i}^{*^{\prime}} \mathbf{X}^{\tau}$ and transfer payments $Q_{i}=\omega_{i} \tau \mathbf{n}_{r}^{\prime}\left(\mathbf{X}_{r}-\mathbf{p}_{r}\right)$, which is an agent's total wealth, i.e., the tradeable and the nontradeable part of wealth: 


$$
\begin{aligned}
W_{i}^{* F}=\mathbf{n}_{i}^{\prime} \mathbf{p}^{* \tau}+\omega_{i} \tau \mathbf{n}_{r}^{\prime}\left(\frac{\mathbf{p}_{r}^{* \tau} R_{\mathrm{f}}^{*}}{R_{\mathrm{f}}^{* \tau}}-\frac{\mathbf{p}_{r}^{* \tau}}{R_{\mathrm{f}}^{* \tau}}\right)=W_{i}^{* F \tau}+W^{* F \tau} \frac{\omega_{i} \tau r_{\mathrm{f}}^{*}}{R_{\mathrm{f}}^{* \tau}} \\
=W_{i}^{* F \tau}+W^{F} \frac{\omega_{i} \tau r_{\mathrm{f}}^{*}}{R_{\mathrm{f}}^{* \tau}}
\end{aligned}
$$

Notice that due to price equality $\mathbf{n}_{r}^{\prime} \mathbf{p}_{r}^{* \tau}=W^{F}=W^{* F \tau}$.

To obtain price equality agents must value the after-tax payoffs in the tax economy equally to the untaxed payoffs in the no-tax economy. For this reason the different values of total wealth must result.

\subsubsection{Marginal utility linear in consumption}

I treat the case of marginal utility linear in consumption, i.e., marginal utility of the form $u_{i}^{\prime}\left(c_{i}\right)=a_{i}+b_{i} c_{i}$. That implies a quadratic utility function. Integration yields $u_{i}\left(c_{i}\right)=a_{i} c_{i}+0.5 b_{i} c_{i}^{2}+d_{i}$, in which $d_{i}$ is a constant. The constant $d_{i}$ just shifts the utility function up or down and has no impact on marginal utility. To have riskaverse agents the second derivative has to be negative, which leads to, $u_{i}^{\prime \prime}\left(c_{i}\right)=b_{i}<0 .{ }^{11} \mathrm{I}$ additionally assume that consumption is nonnegative $\left(c_{i} \geq 0\right)$ and less than or equal to bliss point consumption at $c_{i} \leq c_{i}^{b}=-a_{i} / b_{i}$, which is the extremum of the utility function. Since $b_{i}<0$, for a positive bliss point, $a_{i}$ must be positive as well. Those conditions also ensure positive marginal utility $\left(a_{i}+b_{i} c_{i}>0\right)$.

For an important special case of marginal utility $b_{i}=-1$, so that $a_{i}=c_{i}^{b}$ is the bliss point consumption. Agents have quadratic utility of the form:

$$
u_{i}\left(c_{i}\right)=-0.5\left(c_{i}-c_{i}^{b}\right)^{2} .
$$

This leads to marginal utility linear in consumption of the form,

$$
u_{i}^{\prime}\left(c_{i}\right)=c_{i}^{b}-c_{i}
$$

I use this specification for the tax economy in Eq. (44) and simplify to obtain:

$$
E\left[\left(c_{i}^{b}-c_{i}^{*}\right)\left(\mathbf{X}_{r}-\mathbf{p}_{r}^{* \tau} / p_{0}^{* \tau}\right)\right]=0 .
$$

Summing over agents leads to,

$$
E\left[\left(c^{b}-c^{*}\right)\left(\mathbf{X}_{r}-\mathbf{p}_{r}^{* \tau} / p_{0}^{* \tau}\right)\right]=0 .
$$

This leads to the following proposition:

Proposition 8 In the tax-economy set up above, in which agents have quadratic utility and in which consumption only takes place at $t=1$, the product $\mathbf{p}_{r}^{* \tau} R_{\mathrm{f}}^{*}$, i.e., the ratio $\mathbf{p}_{r}^{* \tau} / p_{0}^{* \tau}$, does not depend on the tax rate. Furthermore, the corresponding

\footnotetext{
${ }^{11}$ With risk-loving agents it is hard to ensure the existence of equilibrium because of non-convexity of preferences. Araujo et al. (2014) show examples of equilibria of economies with risk-averse and riskloving agents.
} 
no-tax economy will have the same product as the tax-economy $\mathbf{p}_{r}^{* \tau} R_{\mathrm{f}}^{*}=\mathbf{p}_{r} R_{\mathrm{f}}$, i.e., the same ratio $\mathbf{p}_{r}^{* \tau} / p_{0}^{* \tau}=\mathbf{p}_{r} / p_{0}$.

Proof Since aggregate consumptions are the same in the tax and the no-tax economy, i.e., $c^{*}=c$, the term $\mathbf{p}_{r}^{* \tau} / p_{0}^{* \tau}$ in Eq. (76) also does not depend on a tax rate.

Quadratic utility implies a mean-variance utility function and the CAPM. It was not mentioned in Kruschwitz and Löffler (2009) as producing equilibria with equal prices. However, the term $\sum_{i=1}^{I} \frac{U_{i E[c]}}{U_{i \mathrm{Var}(c)}}$ is also independent from the tax rate for quadratic utility. Taking expectations of Eq. (73) and expanding the quadratic expression leads to,

$$
\begin{aligned}
E\left[u_{i}\left(c_{i}\right)\right] & =-0.5 E\left[c_{i}^{2}\right]+c_{i}^{b} E\left[c_{i}\right]-0.5 c_{i}^{b 2} \\
& =-0.5 \operatorname{Var}\left(c_{i}\right)-0.5 E\left[c_{i}\right]^{2}+c_{i}^{b} E\left[c_{i}\right]-0.5 c_{i}^{b 2} .
\end{aligned}
$$

It follows that $\frac{U_{i E[c]}}{U_{i \operatorname{Var}(c)}}=2\left(E\left[c_{i}\right]-c_{i}^{b}\right)$ and $\sum_{i=1}^{I} \frac{U_{i E[c]}}{U_{i \operatorname{Var}(c)}}=2\left(E[c]-c^{b}\right)$. Aggregating $c_{i}^{*}$ this way would lead to aggregate consumption in the tax economy, i.e., to $c^{*}$. But aggregate consumptions are the same so that $\sum_{i=1}^{I} \frac{U_{i E[c]}}{U_{i \operatorname{Var}(c)}}=\sum_{i=1}^{I} \frac{U_{i E\left[c^{*}\right]}}{U_{i \operatorname{Var}\left(c^{*}\right)}}$ or $2\left(E[c]-c^{b}\right)=2\left(E\left[c^{*}\right]-c^{b}\right)$.

This can be generalized to any function with marginal utility linear in consumption:

Proposition 9 In the tax-economy set up above, in which agents have utility that leads to linear marginal utility and in which consumption only takes place at $t=1$, the product $\mathbf{p}_{r}^{* \tau} R_{\mathrm{f}}^{*}$, i.e., the ratio $\mathbf{p}_{r}^{* \tau} / p_{0}^{* \tau}$, does not depend on the tax rate. Furthermore, the corresponding no-tax economy will have the same product as the tax-economy $\mathbf{p}_{r}^{* \tau} R_{\mathrm{f}}^{*}=\mathbf{p}_{r} R_{\mathrm{f}}$, i.e., the same ratio $\mathbf{p}_{r}^{* \tau} / p_{0}^{* \tau}=\mathbf{p}_{r} / p_{0}$.

Proof A single agent's pricing equation is:

$$
\mathbf{p}_{r}^{* \tau} / p_{0}^{* \tau}=\frac{E\left[\left(a_{i}+b_{i} c_{i}^{*}\right) \mathbf{X}_{r}\right]}{a_{i}+b_{i} E\left[c_{i}^{*}\right]} .
$$

I aggregate in a fashion similar to Appendix B

$$
\mathbf{p}_{r}^{* \tau} / p_{0}^{* \tau}=E\left[\mathbf{X}_{r} \frac{\sum_{i=1}^{I} \frac{a_{i}}{b_{i}}+c}{\sum_{i=1}^{I} \frac{a_{i}}{b_{i}}+E[c]}\right],
$$

The remainder is the same as in the proof of Proposition 8.

For the portfolio rule it suffices to look at consumption, since marginal utility is a simple linear function of consumption. I use the budget constraint (43) in Eq. (42), which leads to, 


$$
\begin{aligned}
c_{i}^{*}= & \bar{n}_{i 0} X_{0}^{\tau}+\left(\frac{1}{p_{0}^{* \tau}}(1-\tau)\left(\overline{\mathbf{n}}_{i r}^{\prime}-\mathbf{n}_{i r}^{* \prime}\right)+\tau \overline{\mathbf{n}}_{i r}^{\prime}\right) \mathbf{p}_{r}^{* \tau} \\
& +\left(\mathbf{n}_{i r}^{* \prime}(1-\tau)+\omega_{i} \tau \mathbf{n}_{r}^{\prime}\right) \mathbf{X}_{r}-\omega_{i} \tau \mathbf{n}_{r}^{\prime} \mathbf{p}_{r}^{* \tau}
\end{aligned}
$$

The term $\mathbf{n}_{i r}^{* \prime}(1-\tau)+\omega_{i} \tau \mathbf{n}_{r}^{\prime}$ attached to $\mathbf{X}_{r}$ shows that the portfolio rule for risky asset shares is the same as in Proposition 6. Substituting that into the budget constraint also leads to one for the risk-free asset as in Proposition 6. Thus, budget constraints are considered and markets clear as before.

\subsection{Other utility functions}

The cases presented before led to aggregate pricing functions that were independent from the tax rate. Therefore, together with the convenience that the price of the riskfree asset can be chosen, asset prices are the same in the tax and the no-tax economy. For other utility functions, which lead to nonlinear marginal utility, aggregation does not generally lead to an aggregated SDF that is linear in aggregate consumption. For example for power utility of the form $u_{i}\left(c_{i}\right)=\left(c_{i}\right)^{1-\alpha_{i}} /\left(1-\alpha_{i}\right)$ marginal utility is $c_{i}^{-\alpha_{i}}$. Aggregation leads to $\sum_{i=1}^{I} c_{i}^{-\alpha_{i}}$, which does not generally allow a statement in terms of aggregate consumption. Thus, if I use consumption in the tax economy $c_{i}^{*}$, the tax terms remain in the pricing equation, and prices remain dependent on taxes.

\section{Discussion of the results and limitations of the analyses}

\subsection{Some general remarks}

I begin with a general discussion of the results especially with regard to the results derived in Kruschwitz and Löffler (2009). I show in particular that the results in Kruschwitz and Löffler (2009), which are derived for mean-variance optimizing agents, also hold for agents maximizing expected utility over consumption. I additionally stress the result, that a zero risk-free rate leads to tax payments with a price of zero. That makes pre- and after-tax prices as well as wealth before and after taxes and transfers equal. For expositional reasons, I chose to compare an economy with a tax rate of zero and one with a non-zero tax rate. However, the argumentation above can be carried out for any pair of different tax rates. There is no need that one has to be zero. That should be already clear from the fact that to obtain price equality in the tax and the no-tax economy it does not matter what the value of $\tau$ is.

A zero risk-free rate leads to zero prices of capital gains taxes. ${ }^{12}$ By the same token, one could argue that a risk-free rate going to zero makes prices of tax payments going to zero as well. This suggests that price distortions through the tax can be reduced and even be eliminated through changing the risk-free rate towards

\footnotetext{
12 A zero risk-free rate is difficult to obtain. Even though rates are currently very low especially in Europe, this is not the usual condition. There are many further issues such as that we only observe proxies of risk-free rates and that those rates usually have a non-flat term structure.
} 
to zero. However, there are some problems with this argumentation. First, when there is the possibility of more than one equilibrium, one cannot be sure that the introduction of capital gains taxes or a change of the tax rate will lead to the equilibrium that corresponds to the equilibrium before the change and therefore leaves prices unchanged. Kruschwitz and Löffler (2009) also mention that the CAPM typically has several equilibria with different price vectors. They show that there exists at least one equilibrium with an unchanged price vector when taxes are introduced. The CAPM does not rely on complete markets so that there is no market completeness that would contribute to a unique solution. For the case herein, if there is a single solution, the portfolio changes derived herein are consistent with price equality and with the same consumption streams of agents before and after the tax rate change. The second problem is that the argumentation of making the risk-free rate zero leaves the question open on how this is done. If the risk-free rate is exogenous to the economy, one can leave all else equal and change the rate towards zero to reduce price distortions. However, if the risk-free rate is endogenous one cannot just change the risk-free rate leaving all else equal. Then, there exist some more fundamental causes that change the risk-free rate.

In practice, the tax system is much more complex than the one set up here. For example, the tax system outlined here is symmetric in the way that positive and negative capital gains are taxed equally. This is crucial to obtain the result of a zero price of taxes with a zero risk-free rate. In the U.S. negative capital gains can be deducted from taxes only up to 3000 USD and there need to be taxes paid in the first place to have something to deduct the losses from. ${ }^{13}$ Introducing more periods and tax losses that can be carried forward complicates the analysis even more. Thus, a more realistic tax system at least weakens the conclusions drawn here. The consequences of a more realistic tax code show scope for future research on the topic.

For the model with consumption at $t=0$ and $t=1$ the risk-free rate is endogenous. I show that with linear marginal utility, there can never be price equality for a risk-free rate not equal to zero. This is because the prices of the riskfree assets differ in the tax and the no-tax economy. However, when consumption takes place only at $t=1$ so that the risk-free assets' prices are exogenous and chosen to be equal, price equality can be established for linear marginal utility as well.

Without a zero risk-free rate but with exponential utility (CARA utility) and multivariate normal payoffs there is again an equilibrium that is consistent with unchanged prices. Exponential utility implies constant absolute risk aversion and increasing relative risk aversion (IRRA) (Lengwiler 2004, p. 92). This utility specification is convenient because together with the normality assumption it leads to the CAPM. But it is not how we think about the characteristics of economic agents. Decreasing absolute risk aversion (DARA) and constant relative risk aversion (CRRA) seem intuitively and empirically to be more realistic (Lengwiler 2004, p. 87).

\footnotetext{
${ }^{13}$ For further reference on rules for the treatment of capital gains and losses in the U.S. see https://www. irs.gov/taxtopics/tc409.html.
} 
Having noted this, and looking at the current situation with relatively low real and nominal rates in Europe and the U.S., I will provide a simple numerical example on asset price distortions through different capital gains tax rates and different riskfree rates.

\subsection{A simple example with quadratic utility and consumption at $t=0$ and $t=1$}

\subsubsection{Model specification and base case with a zero risk-free rate}

I use a simple model with two agents $I=2$, two risky assets $N=2$, and a risk-free asset. There are three states and the payoffs are not redundant so that the asset market is complete. I set the time discount factors of the agents to one, so that I do not have to consider them explicitly here. I summarize the characteristics of the two agents in Table 1.

The payoff space is specified as follows:

$$
\mathbf{X}=\left[\begin{array}{l}
111 \\
0.420 \\
003
\end{array}\right]
$$

As before rows are assets and columns are states. Since the risk-free asset is in zero

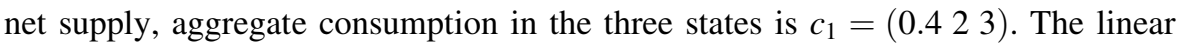
marginal utility of the agents leads to simple expressions for the SDFs with,

$$
m_{i}=\frac{c_{i}^{b}-c_{i 1}}{c_{i}^{b}-c_{i 0}},
$$

for $i=1,2$. Due to market completeness the SDFs of the two agents are equal. Furthermore, due to the linearity of marginal utility of consumption, the SDF can be represented through aggregate consumption and aggregate bliss point consumption:

$$
m_{i}=\frac{c_{i}^{b}-c_{i 1}}{c_{i}^{b}-c_{i 0}}=\frac{c^{b}-c_{1}}{c^{b}-c_{0}},
$$

for $i=1,2$. To see that one can write down the vector of prices in the form:

Table 1 Characteristics of agents

\begin{tabular}{llll}
\hline Parameter & Agent 1 & Agent 2 & Aggregate \\
\hline$c_{i}^{b}$ & 1.5 & 2 & 3.5 \\
$\bar{c}_{i 0}$ & 0 & 1 & 1 \\
$\overline{\mathbf{n}}_{i}^{\prime}$ & $\left(\begin{array}{lll}0 & 1 & 1\end{array}\right)$ & $\left(\begin{array}{lll}0 & 0 & 0\end{array}\right)$ & $\left(\begin{array}{lll}0 & 1 & 1\end{array}\right)$ \\
\hline
\end{tabular}




$$
\mathbf{p}=E\left[\frac{c_{i}^{b}-c_{i 1}}{c_{i}^{b}-c_{i 0}} \mathbf{X}\right]
$$

and multiply both sides by $c_{i}^{b}-c_{i 0}$. The resulting expression is $\left(c_{i}^{b}-c_{i 0}\right) \mathbf{p}=$ $E\left[\left(c_{i}^{b}-c_{i 1}\right) \mathbf{X}\right]$ for $i=1,2$. Now, one can simply add up those expressions for the two agents to obtain $\left(c_{1}^{b}-c_{10}+c_{2}^{b}-c_{20}\right) \mathbf{p}=E\left[\left(c_{1}^{b}-c_{11}+c_{2}^{b}-c_{21}\right) \mathbf{X}\right]$, which is the same as $\left(c^{b}-c_{0}\right) \mathbf{p}=E\left[\left(c^{b}-c_{1}\right) \mathbf{X}\right]$, and can be rearranged to

$$
\mathbf{p}=E\left[\frac{c^{b}-c_{1}}{c^{b}-c_{0}} \mathbf{X}\right] .
$$

I summarize statewise the probabilities $\pi_{s}$, the elements of the SDF $m_{s}$ and state prices $\kappa_{s}$ for $s=1,2,3$ in Table 2 . The SDF is given through aggregate consumption and the aggregate bliss points. I choose the probabilities so that I obtain a zero risk-free rate, i.e., a gross risk-free rate of one. This can be verified through summing up the state prices in the table, which sum up to 1.

That allows to compute the asset prices, which are $\mathbf{p}^{\prime}=\left(\begin{array}{lll}1.00 & 0.63 & 0.05\end{array}\right)$. To obtain portfolio weights I use the fact that $m=\left(c_{i}^{b}-c_{i 1}\right) /\left(c_{i}^{b}-c_{i 0}\right)$. I substitute $c_{i 1}=\mathbf{n}_{i}^{\prime} \mathbf{X}$ and $c_{i 0}=\left(\overline{\mathbf{n}}_{i}^{\prime} \mathbf{p}+\bar{c}_{i 0}\right)-\mathbf{n}_{i}^{\prime} \mathbf{p}$ into this expression and rearrange for portfolio weights. This yields:

$$
\mathbf{n}_{i}^{\prime}=\left(c_{i}^{b}+\left(\left(\overline{\mathbf{n}}_{i}^{\prime} \mathbf{p}+\bar{c}_{i 0}\right)-c_{i}^{b}\right) m\right)(\mathbf{p} m+\mathbf{X})^{-1} .
$$

I use this equation to compute portfolio weights $\mathbf{n}_{i}$, initial consumption $c_{i 0}$, wealth after initial consumption $W_{i}^{F}$, and consumption at $t=1$ for the different states $c_{i 1}$. Table 3 summarizes this information.

The table shows that the agents put equal weights on the risky assets. Quadratic utility implies the CAPM (Cochrane 2005, p. 153), which, in turn, implies that every agent holds a share of the portfolio of risky assets. Thus, every agent must hold the same share of every risky asset.

Table 2 Summary of pricing components

\begin{tabular}{lllr}
\hline States $s$ & $\pi_{s}$ & $m_{s}$ & $\kappa_{s}$ \\
\hline 1 & 0.67 & 1.24 & 0.83 \\
2 & 0.25 & 0.60 & 0.15 \\
3 & 0.08 & 0.20 & 0.02 \\
\hline
\end{tabular}

Table 3 Summary of agents' portfolios, consumption and wealth in the no-tax economy

\begin{tabular}{llllll}
\hline Agent $i$ & \multicolumn{1}{l}{$\mathbf{n}_{i}$} & $c_{i 0}$ & $W_{i}^{F}$ & \multicolumn{1}{l}{$c_{i 1}$} \\
\hline 1 & $\left(\begin{array}{lllll}-0.03 & 0.44 & 0.44\end{array}\right)$ & 0.41 & 0.27 & $\left(\begin{array}{lllll}0.15 & 0.85 & 1.28\end{array}\right)$ \\
2 & $\left(\begin{array}{lllll}0.03 & 0.56 & 0.56\end{array}\right)$ & 0.59 & 0.41 & $\left(\begin{array}{llll}0.25 & 1.15 & 1.72\end{array}\right)$ \\
$1+2$ & $\left(\begin{array}{lllll}0.00 & 1.00 & 1.00\end{array}\right)$ & 1.00 & 0.68 & $\left(\begin{array}{llll}0.40 & 2.00 & 3.00\end{array}\right)$ \\
\hline
\end{tabular}


Table 4 Summary of agents' portfolios, consumption and wealth in the tax economy

\begin{tabular}{lllllll}
\hline Agent $i$ & $\mathbf{n}_{i}^{*}$ & $c_{i 0}^{*}$ & $W_{i}^{* F}$ & $c_{i 1}^{*}$ & \\
\hline 1 & $\left(\begin{array}{llllllll}-0.09 & 0.53 & 0.53\end{array}\right)$ & 0.41 & 0.27 & $\left(\begin{array}{lllll}0.15 & 0.85 & 1.28\end{array}\right)$ \\
2 & $\left(\begin{array}{lllll}0.09 & 0.47 & 0.47\end{array}\right)$ & 0.59 & 0.41 & $\left(\begin{array}{llll}0.25 & 1.15 & 1.72\end{array}\right)$ \\
$1+2$ & $\left(\begin{array}{lllll}0.00 & 1.00 & 1.00\end{array}\right)$ & 1.00 & 0.68 & $\left(\begin{array}{llll}0.40 & 2.00 & 3.00\end{array}\right)$ \\
\hline
\end{tabular}

In the tax economy the SDF does not change because aggregate consumption does not change. I again use the fact that $m^{*}=m=\left(c_{i}^{b}-c_{i 1}^{*}\right) /\left(c_{i}^{b}-c_{i 0}^{*}\right)$. The tax rate $\tau$ is $40 \%$. I substitute $c_{i 1}^{*}=\mathbf{n}_{i}^{* \prime}\left(\mathbf{X}-\tau\left(\mathbf{X}-\mathbf{p}^{* \tau}\right)\right)+\omega_{i} \tau \mathbf{n}^{\prime}\left(\mathbf{X}-\mathbf{p}^{* \tau}\right)$ and $c_{i 0}=\left(\overline{\mathbf{n}}_{i}^{\prime} \mathbf{p}^{* \tau}+\right.$ $\left.\bar{c}_{i 0}\right)-\mathbf{n}_{i}^{\prime} \mathbf{p}^{* \tau}$ into this expression and rearrange for portfolio weights. This yields:

$$
\begin{aligned}
\mathbf{n}_{i}^{* \prime}= & \left(c_{i}^{b}+\left(\left(\overline{\mathbf{n}}_{i}^{\prime} \mathbf{p}^{* \tau}+\bar{c}_{i 0}\right)-c_{i}^{b}\right) m-\omega_{i} \tau \mathbf{n}^{\prime}\left(\mathbf{X}-\mathbf{p}^{* \tau}\right)\right) \\
& \times\left(\mathbf{p}^{* \tau} m+\mathbf{X}(1-\tau)+\tau \mathbf{p}^{* \tau}\right)^{-1} .
\end{aligned}
$$

I use this expression to compute portfolio weights $\mathbf{n}_{i}^{*}$, initial consumption $c_{i 0}^{*}$, wealth after consumption $W_{i}^{* F}$, and consumption at $t=1$ for the different states. The results are presented in Table 4.

Expectedly, the only change compared to the result in Table 2 is the change in the portfolio weights. Alternatively to Eq. (88), one can also use the expression in Proposition 4 rearranged for $\mathbf{n}_{i}^{* \prime}$, which yields exactly the same portfolios weights, which, in turn, imply equal consumption in both economies. I continue to look at effects of changes in the risk-free rate on prices.

\subsubsection{Price distortions through a non-zero risk-free rate}

In the constructed model the risk-free rate is endogenous. Thus, there must be a change in the basic economy to induce a change in the risk-free rate. I alter the riskfree rate through using different probabilities of the states, and I hold the remaining parameters constant. This leaves the SDF unchanged but leads to new state prices. Notice that with quadratic utility and $\beta_{i}=1$ for all $i, E[m]=1$ means that,

$$
E\left[\frac{c^{b}-c_{1}}{c^{b}-c_{0}}\right]=1
$$

which implies that $E\left[c_{1}\right]=c_{0}$ or zero expected consumption growth. Changing bliss point consumption changes prices but will eventually not lead to a zero risk-free rate. With an impatience factor $\beta$ equal for all agents and not equal to one, it is possible to change bliss point consumption so that a zero risk-free rate can be obtained.

The endogeneity of the risk-free rate makes clear that a change in the risk-free rate is triggered by some fundamental change in the economy. Thus, it is not instructive to compare the pair of a no-tax and a tax economy at a zero risk-free rate with a pair of economies at a different risk-free rate. Furthermore, the same value for the risk-free rate can be obtained through different changes of fundamental parameters, leading to different prices and price differences in both economies. Therefore, I restrict the analysis to changes in the probabilities of states one and three. 
To compute a target risk-free rate $R_{\mathrm{f}}^{T}$, I use the fact that $1 / R_{\mathrm{f}}^{T}=E[m]=m_{1} \pi_{1}+m_{2} \pi_{2}+m_{3} \pi_{3}$, where the subscripts in the last equality are states. Probabilities must sum to 1 so that $1 / R_{\mathrm{f}}^{T}=m_{1} \pi_{1}+m_{2} \pi_{2}+m_{3}\left(1-\pi_{1}-\pi_{2}\right)$. I rearrange for $\pi_{1}$ :

$$
\pi_{1}=\frac{1 / R_{\mathrm{f}}^{T}-m_{2} \pi_{2}-m_{3}+m_{3} \pi_{2}}{m_{1}-m_{3}} .
$$

Probability $\pi_{2}$ remains unchanged and $\pi_{3}=1-\pi_{1}-\pi_{2}$.

The model with quadratic utility is very convenient to compute price differences because the discount factor does not change when going from the no-tax to the tax economy. Since the SDF does not change, the pre-tax price in the tax economy is equal to the price in the no-tax economy: $\mathbf{p}^{*}=\mathbf{p}$. That holds for any risk-free rate, but it is special to the quadratic utility. Therefore, I can use Eq. (17), in which I substitute in $p_{j}$ for $p_{j}^{*}$ and $1 / R_{\mathrm{f}}^{* \tau}$ for $E\left[m^{*}\right]$ :

$$
p_{j}^{* \tau}=\frac{p_{j}(1-\tau)}{1-\tau / R_{\mathrm{f}}^{* \tau}} .
$$

I rearrange Eq. (91) to an expression that yields the price difference in percent of price in the tax economy:

$$
\frac{p_{j}-p_{j}^{* \tau}}{p_{j}^{* \tau}}=\frac{1-\tau / R_{\mathrm{f}}^{* \tau}}{1-\tau}-1 .
$$

Thus, for quadratic utility the percentage change in price versus the no-tax case is the same for any asset $j$. As the prior equation shows, the rhs does not depend on any asset specific parameter.

The unchanged SDF between the no-tax and the tax economy also means that the risk-free rate in the no-tax economy is equal to the after-tax risk-free rate in the tax economy: $R_{\mathrm{f}}=1 / E[m]=1 / E\left[m^{*}\right]=R_{\mathrm{f}}^{* \tau}$. I show the results for some ranges of the after-tax risk-free rate and the tax rate in Table 5. I also provide the implied pre-tax risk-free rates on the rhs of the table.

Table 5 Price changes through capital gains taxes for different risk-free rates

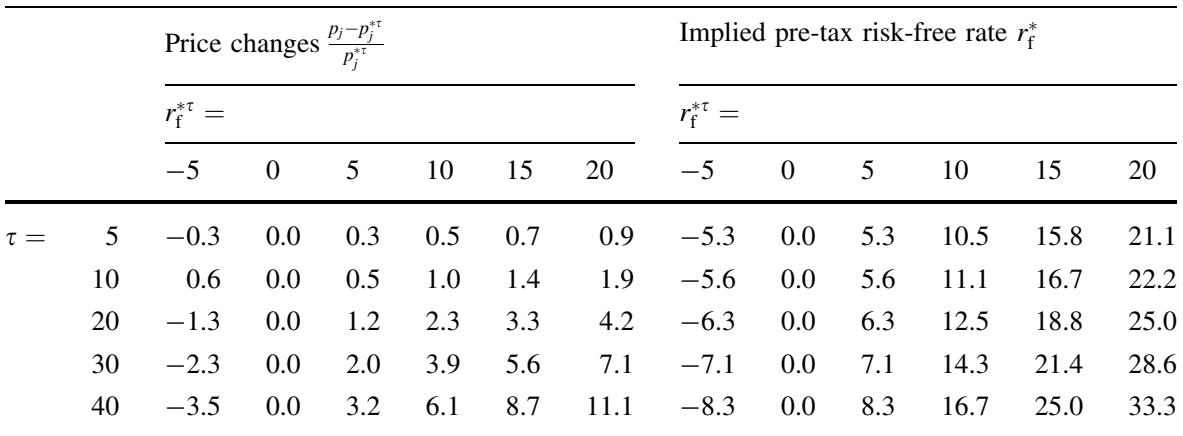

All numbers are in percent and rounded to one decimal 
Table 6 Summary of agents' portfolios, consumption and wealth in the no-tax and the tax economy

\begin{tabular}{|c|c|c|c|c|}
\hline Agent $i$ & $\mathbf{n}_{i}$ & $c_{i 0}$ & $W_{i}^{F}$ & $c_{i 1}$ \\
\hline \multicolumn{5}{|c|}{ No-tax economy } \\
\hline 1 & $\left(\begin{array}{lll}-0.02 & 0.44 & 0.44\end{array}\right)$ & 0.41 & 0.28 & $\left(\begin{array}{lll}0.15 & 0.85 & 1.28\end{array}\right)$ \\
\hline 2 & $\left(\begin{array}{lll}0.02 & 0.56 & 0.56\end{array}\right)$ & 0.59 & 0.41 & $\left(\begin{array}{lll}0.25 & 1.15 & 1.72\end{array}\right)$ \\
\hline Agent $i$ & $\mathbf{n}_{i}^{*}$ & $c_{i 0}^{*}$ & $W_{i}^{* F \tau}$ & $c_{i 1}^{*}$ \\
\hline \multicolumn{5}{|c|}{ Tax economy } \\
\hline 1 & $\left(\begin{array}{lll}-0.13 & 0.54 & 0.54\end{array}\right)$ & 0.39 & 0.24 & $\left(\begin{array}{lll}0.12 & 0.83 & 1.28\end{array}\right)$ \\
\hline 2 & $\left(\begin{array}{lll}0.13 & 0.46 & 0.46\end{array}\right)$ & 0.61 & 0.39 & $\left(\begin{array}{lll}0.28 & 1.17 & 1.72\end{array}\right)$ \\
\hline
\end{tabular}

The assumed tax rate is $40 \%$ and $r_{\mathrm{f}}^{* \tau}=20 \%$

The table shows that a higher risk-free rate increases the price difference between prices in the tax economy and those in the no-tax economy. For example for $r_{\mathrm{f}}^{* \tau}=20 \%$ and a tax rate of $5 \%$ the prices in the no-tax economy are $0.9 \%$ higher than in the tax economy. For $r_{\mathrm{f}}^{* \tau}=-5 \%$ the prices in the no-tax economy are $0.3 \%$ less than the ones in the tax economy. The columns of the table show that the magnitudes increase with an increasing tax rate.

I show the effects of the combination $\tau=40 \%$ and $r_{\mathrm{f}}^{* \tau}=20 \%$ a bit more in detail. The price vector in the no-tax economy is then $\mathbf{p}^{\prime}=\left(\begin{array}{lll}0.83 & 0.55 & 0.14\end{array}\right)$, which means that assets are worth 0.69 (the last two prices). In the tax economy the price vector is $\mathbf{p}^{* \tau \prime}=\left(\begin{array}{lll}0.750 .50 & 0.13\end{array}\right)$, so that the total value of financial assets amounts to 0.63 . The differences of the values reflect the $11.1 \%$ given in Table 5.

Consumption in $t=0$ and $t=1$ as well as wealth are different between the economies. Notice, however, that the agents' consumption does not change a lot (Table 6). They try to stick to the pattern that was optimal without taxes. The tax transfers, which now have a non-zero price, cannot be traded at $t=0$ so that agents have to rearrange what they want to consume now and what they want to save for the next period. With quadratic utility they can do that without changing the SDF. In the no-tax economy agents can trade all of the claims on future consumption, which leads to a different division of endowments into initial consumption and wealth, as well as to a changed future consumption.

Still with a complete asset market but with a more demanding utility function such as power utility, aggregation of marginal utilities is more complicated and does not involve just summing up consumption of agents. It involves summing over nonlinear functions of consumption. That means introducing taxes will likely not leave the SDF unchanged, which in turn can lead to different risk-free rates in the two economies. Then, something like Table 5 needs a new interpretation because $r_{\mathrm{f}}^{* \tau}=r_{\mathrm{f}}$ is not likely to hold anymore. 


\section{Conclusion}

I extend the analysis of Kruschwitz and Löffler (2009) about the effects of capital gains taxes on asset pricing. Specifically, they analyze cases when taxes do not change prices in a mean-variance CAPM with consumption only at one future point in time. I extend the analysis to agents who maximize expected utility over consumption. I construct two economies that have equal endowments, utility functions of investors and payoffs. I look at economies with consumption at $t=0$ and $t=1$. I find that, with a risk-free rate of zero, taxes on returns have zero value. Using this result, I can show that for a no-tax economy there exists a tax economy with the same asset prices. This is the case when investors change their portfolios to consume the same in the tax economy in every state as in the no-tax economy. This implies the same portfolio rule as proposed in Kruschwitz and Löffler (2009). With a non-zero risk-free rate equilibria with equal prices and in which agents consume the same in the tax as in the no-tax economy do not generally exist. In the case of linear marginal utility, prices are always different in both economies for a non-zero risk-free rate.

Furthermore, I show that with exponential utility, multivariate normal payoffs, and consumption only in $t=1$, prices are equal when the risk-free rate in both economies are the same. But this time taxes do not have zero value so that aggregate wealth after initial consumption is different in both economies. Individual consumption profiles as well as SDFs are different in the two economies. I find that the portfolio rule for risky assets is the same as in Kruschwitz and Löffler (2009) and the same is true for the case with a zero risk-free rate and in which all agents consume the same in both economies in every state. Additionally, utility functions that lead to linear marginal utility also have equilibria with equal prices. Aggregation makes the pricing equation independent from the tax rate. With nonlinear marginal utility, price equality cannot generally be obtained since aggregation will keep the tax rate terms in the aggregate pricing equation. Eventually, also in the case with consumption only at $t=1$, a zero risk-free rate leads equal price vectors for the two economies.

Open Access This article is distributed under the terms of the Creative Commons Attribution 4.0 International License (http://creativecommons.org/licenses/by/4.0/), which permits unrestricted use, distribution, and reproduction in any medium, provided you give appropriate credit to the original author(s) and the source, provide a link to the Creative Commons license, and indicate if changes were made.

\section{Appendix A: Alternative derivation for the exponential utility case with multivariate normal payoffs}

Another approach to obtain the same the pricing equation but to keep more track of the SDF language is to use Stein's lemma. The SDF is a function of consumption, which, in turn, is normally distributed. The vector $\mathbf{X}_{r}^{\tau}$ still contains the tax expression so that I can rearrage $\mathbf{p}_{r}^{* \tau}=E\left[m_{i}^{*} \mathbf{X}_{r}^{\tau}\right]$ to obtain the known equation $\mathbf{p}_{r}^{* \tau}=E\left[m_{i}^{*} \mathbf{X}_{r} \frac{R_{\mathrm{f}}^{* \tau}}{R_{\mathrm{f}}^{*}}\right]$. 
I use the definition for the SDF, i.e., $m_{i}^{*}=\frac{u_{i}^{\prime}\left(c_{i}^{*}\right)}{R_{\mathrm{f}}^{* \tau} E\left[u_{i}^{\prime}\left(c_{i}^{*}\right)\right]}$. Assuming multivariate normal payoffs, I use Stein's Lemma for the pricing equation:

$$
\begin{aligned}
\mathbf{p}_{r}^{* \tau} & =E\left[m_{i}^{*} \mathbf{X}_{r} \frac{R_{\mathrm{f}}^{* \tau}}{R_{\mathrm{f}}^{*}}\right]=\frac{E\left[\mathbf{X}_{r}\right]}{R_{\mathrm{f}}^{*}}+\operatorname{Cov}\left(m_{i}^{*}, \mathbf{X}\right) \frac{R_{\mathrm{f}}^{* \tau}}{R_{\mathrm{f}}^{*}} \\
& =\frac{E\left[\mathbf{X}_{r}\right]}{R_{\mathrm{f}}^{*}}+\operatorname{Cov}\left(u_{i}^{\prime}\left(c_{i}^{*}\right), \mathbf{X}_{\mathbf{r}}\right) \frac{1}{R_{\mathrm{f}}^{*} E\left[u_{i}^{\prime}\left(c_{i}^{*}\right)\right]} \\
& =\frac{E\left[\mathbf{X}_{r}\right]}{R_{\mathrm{f}}^{*}}+E\left[u_{i}^{\prime}\left(c_{i}^{*}\right)\right] \operatorname{Cov}\left(c_{i 1}^{*}, \mathbf{X}_{r}\right) \frac{1}{R_{\mathrm{f}}^{*} E\left[u_{i}^{\prime}\left(c_{i}^{*}\right)\right]} \\
& =\frac{E\left[\mathbf{X}_{r}\right]}{R_{\mathrm{f}}^{*}}+E\left[u_{i}^{\prime}\left(c_{i}^{*}\right)\right] \Omega\left(\mathbf{n}_{r i}^{*}(1-\tau)+\omega_{i} \tau \mathbf{n}_{r}\right) \frac{1}{R_{\mathrm{f}}^{*} E\left[u_{i}^{\prime}\left(c_{i}^{*}\right)\right]} .
\end{aligned}
$$

Marginal utility of consumption at $t=1$ is:

$$
u_{i}^{\prime}\left(c_{i 1}^{*}\right)=\exp \left(-\alpha_{i} c_{i 1}^{*}\right) .
$$

The second derivative with respect to $c_{i 1}^{*}$ is:

$$
u_{i}^{\prime \prime}\left(c_{i 1}^{*}\right)=-\alpha_{i} \exp \left(-\alpha_{i} c_{i 1}^{*}\right)=-\alpha_{i} u_{i}^{\prime}\left(c_{i 1}^{*}\right) .
$$

I substitute this back into Eq. (93) to obtain:

$$
\mathbf{p}_{r}^{* \tau}=\frac{E\left[\mathbf{X}_{r}\right]}{R_{\mathrm{f}}^{*}}-\frac{\alpha}{R_{\mathrm{f}}^{*}} \Omega\left(\mathbf{n}_{r i}^{*}(1-\tau)+\omega_{i} \tau \mathbf{n}_{r}\right) .
$$

This is the same as Eq. (53), which can be aggregated to Eq. (55). For the no-tax economy, using Stein's Lemma gives:

$$
\mathbf{p}=\frac{E[\mathbf{X}]}{R_{\mathrm{f}}}+-\frac{\alpha_{i}}{R_{\mathrm{f}}} \Omega \mathbf{n}_{r i} .
$$

With equal prices so that also $R_{\mathrm{f}}^{*}=R_{\mathrm{f}}$, Eqs. (93) and (97) lead to,

$$
\mathbf{n}_{r i}^{*}(1-\tau)+\omega_{i} \tau \mathbf{n}_{r}=\mathbf{n}_{r i},
$$

which is expectedly the same portfolio rule derived earlier. Using the budget constraints leads to the same rule for the risk-free asset as before.

\section{Appendix B: Linear marginal utility and aggregation}

I denote a general form of linear marginal utility as $u^{\prime}\left(c_{i 1}\right)=a_{i}+b_{i} c_{i 1}$, so that the individual SDF for the model with consumption at times $t=0$ and $t=1$ is:

$$
m_{i 1}=\beta \frac{a_{i}+b_{i} c_{i 1}}{a_{i}+b_{i} c_{i 0}} .
$$

Putting that into Eq. (5) and multiplying by $\left(a_{i}+b_{i} c_{i 0}\right)$, I obtain: 


$$
\mathbf{p}\left(a_{i}+b_{i} c_{i 0}\right)=E\left[\mathbf{X} \beta\left(a_{i}+b_{i} c_{i 1}\right)\right] .
$$

I divide by $b_{i}$ and sum over all $i$ to obtain:

$$
\mathbf{p}\left(\sum_{i=1}^{I} \frac{a_{i}}{b_{i}}+c_{0}\right)=E\left[\mathbf{X} \beta\left(\sum_{i=1}^{I} \frac{a_{i}}{b_{i}}+c_{1}\right)\right],
$$

in which $c_{0}=\sum_{i=1}^{I} c_{i 0}$ and $c_{1}=\sum_{i=1}^{I} c_{i 1}$. Rearranging again leads to,

$$
\mathbf{p}=E\left[\mathbf{X} \beta \frac{\sum_{i=1}^{I} \frac{a_{i}}{b_{i}}+c_{1}}{\sum_{i=1}^{I} \frac{a_{i}}{b_{i}}+c_{0}}\right] .
$$

Aggregate values for consumption can be used in the SDF. For the form of quadratic utility that is used in Cochrane (2014) and also herein, i.e., for $u\left(c_{i t}\right)=-0.5\left(c_{i t}-c_{i}^{b}\right)^{2}$, marginal utility is $c_{i t}-c_{i}^{b}$, so that $b_{i}=-1$ for all $i$ and $a_{i}=c_{i}^{b}$. Notice that the time discount factors $\beta$ are equal for all agents. With different time discount factors the equation changes to,

$$
\mathbf{p}=E\left[\mathbf{X} \frac{\sum_{i=1}^{I} \frac{a_{i}}{b_{i}}+c_{1}}{\sum_{i=1}^{I} \frac{1}{\beta_{i}}\left(\frac{a_{i}}{b_{i}}+c_{0 i}\right)}\right],
$$

which shows that aggregate consumption at $t=0$ cannot generally be used in the SDF.

\section{References}

Araujo, A., A. Chateauneuf, J. Gama-Torres, and R. Novinski. 2014. General equilibrium, risk taking and volatility. http://www.ipag.fr/fr/accueil/la-recherche/publications-WP.html. Accessed 20 Nov 2017.

Brennan, M.J. 1970. Taxes, market valuation and corporate financial policy. National Tax Journal 23 (4): 417-427.

Cochrane, J.H. 2005. Asset Pricing/Revised Edition. Princeton: Princeton University Press.

Cochrane, J.H. 2014. A mean-variance benchmark for intertemporal portfolio theory. The Journal of Finance 69 (1): 1-49.

Eikseth, H.M., and S. Lindset. 2009. A note on capital asset pricing and heterogeneous taxes. Journal of Banking and Finance 33: 573-577.

Kruschwitz, L., and S. Husmann. 2012. Finanzierung und Investition, vol 7. Munich: Oldenbourg Verlag.

Kruschwitz, L., and J. Löffler. 2009. Do taxes matter in the capm? BuR-Business Research 2 (2): $171-178$.

Lajeri-Chaherli, F., and L.T. Nielsen. 1993. Risk aversion and prudence: The case of mean-variance preferences. Working Paper 93/21/FIN/EP.

Lengwiler, Y. 2004. Microfoundations of Financial Economics. Princeton: Princeton University Press.

Meyer, J. 1987. Two-moment decision models and expected utility maximization. The American Economic Review 77 (3): 421-430.

Sialm, C. 2006. Stochastic taxation and asset pricing in dynamic general equilibrium. Journal of Economic Dynamics \& Control 30 (3): 511-540.

Sialm, C. 2009. Tax changes and asset pricing. American Economic Review 99 (4): 1356-1383.

Wiese, J. 2007. Unternehmensbewertung und Abgeltungssteuer. Die Wirtschaftprüfung 60 (9): 368-375.

Williams, G. 1990. Overdetermined system of linear equations. The American Mathematical Monthly 97 (6): 511-513. 